\title{
«Sprache, «Nation» und «Identität» im sprachpolitischen Diskurs Kataloniens
}

\section{Einleitung}

Das schottische Parlament hielt im März 2000 erstmals nach mehr als 600 Jahren eine Sitzung in gälischer Sprache ab. Jedoch beherrschten nur drei der Abgeordneten dieses Idiom. Die restlichen 126 verfolgten die Debatte in Simultanübersetzung per Kopfhörer (jungle world 06.09.2000). Dies ist ein Beispiel dafür, wie sehr Sprache heute nicht mehr nur als reines Instrument der Kommunikation gesehen wird, sondern als Symbol «nationaler Identitäten» fungiert. Nicht nur in Schottland, auch in Spaniens Regionen Katalonien, Baskenland und Galicien und auch in Wales, Flandern, Korsika, in der französischen Bretagne und in Norditalien fordern Minderheiten die Förderung der eigenen Sprache und gleichzeitig die Anerkennung ihrer «nationalen Identität».

Keine Wissenschaft bleibt je von diskursiven Trends unangetastet, kann «frei existieren [...], nur der 〈Wahrheit> und der Demokratie verpflichtet und der Verbesserung der menschlichen Lebensbedingungen, sondern [ist] abhängig [...] von den jeweils politisch und ökonomisch Herrschenden, von ihren 〈Wahrheiten〉, ihren Interessen und politischen Präferenzen, oder anders: vom hegemonialen, also vom vorherrschenden gesellschaftlichen Diskurs» (Jäger 2004, 33). Es ist daher nicht verwunderlich, dass das Interesse der Sprachwissenschaft an Minderheitssprachen sich genau in dem Moment potenzierte, als sich das Erstarken der Minderheitsbewegungen (v.a. in Europa) abzeichnete.

Im vorliegenden Aufsatz soll eine Reflektion darüber angeregt werden, inwieweit die Sprachwissenschaften im Bereich der Minderheitssprachenförderung ihre Argumentation an einem politischen Trend orientieren. Als Grundlage dient die Analyse sprachpolitischer Diskurse in Katalonien. Diese basiert auf Reden des Politikers Jordi Pujol, der von 1980 bis 2003 Präsident der Generalitat (Autonomieregierung) von Katalonien war, und Texten katalanischer Soziolinguisten, die die Förderung der katalanischen Sprache unterstützen.

Zur Korpusauswahl ist folgendes zu sagen: Ich beziehe mich auf zwei Reden Jordi Pujols von 1995, eine vom 20. März 1995 («Acte institucional commemoratiu del 15è aniversari d'autogovern de Catalunya») und eine vom 22. März 1995 («Què representa la llengua a Catalunya?»). Die Wahl fiel gerade auf diese, da sie sich besonders intensiv mit dem Thema Spra- 
che beschäftigen. Nur punktuell werden auch Äußerungen Pujols aus anderen Zusammenhängen zitiert.

Als Untersuchungsgrundlage des Diskurses katalanischer Soziolinguisten habe ich zwei Werke von Albert Branchadell Gallo gewählt. Dieser katalanische Philologe und Soziolinguist lehrt an der Universitat Autónoma de Barcelona und ist Mitglied der Organització pel Multilingüisme. Beide ausgewählten Werke («La normalitat improbable: obstacles a la normalització lingüística» von 1996 und «Liberalisme i normalització lingüística» von 1997) stammen aus den 90er Jahren, also aus der Zeit vor der Verabschiedung des zweiten Sprachgesetzes (1997), so dass sie in den gleichen zeitlichen Kontext gehören wie die beiden Reden Pujols. Albert Branchadell informiert hier jedoch auch allgemein über die Argumentation für die katalanische Sprachpolitik und sammelt Zitate verschiedener Akteure, denen weiter nachgegangen oder die, wenn die Originalquellen in Deutschland schwer erhältlich waren, übernommen wurden. Die Lektüre Branchadells ergab außerdem Hinweise auf wichtige Werke und Aufsätze, die den Diskurs der 90er Jahre weiterhin prägten (was ihre Aufnahme in Branchadells Werk ja zeigt), so dass sie trotz ihrer Loslösung vom Zeitkontext angeführt werden.

Zum besseren theoretischen Verständnis soll im folgenden zunächst eine kurze Darstellung der Diskurstheorie gegeben und über ihre Verwendbarkeit in einer sprachwissenschaftlichen Theorie der Sprachpolitik nachgedacht werden.

\section{Diskursanalyse: Theorie und Methode}

Grundidee der Diskurstheorie, die in den Werken des französischen Philosophen Michel Foucault ihre Grundlage hat, ist, dass Sprache Wirklichkeit nicht abbildet, sondern schafft: Das als «Wahrheit» angesehene wird diskursiv produziert. Es ist jedoch nicht so, als ob in Diskursen reine Illusionen produziert würden, die nicht greifbar wären. Vielmehr schaffen sie Tatsachen: Die Sprache bezeichnet die Dinge nicht nur, sie schafft Deutungsmuster (Wissen), an denen die Menschen ihr Handeln orientieren. Diese Handlungen sind und schaffen Wirklichkeit. Diskurse sind daher auch «als Praktiken zu behandeln, die systematisch die Gegenstände bilden, von denen sie sprechen» (Foucault 1981, 74).

Die Methodologie der Diskurstheorie ist noch sehr unterentwickelt. Es existiert keine einheitlich festgelegte Vorgehensweise. Auch Foucault selbst hat kein konkretes methodologisches Programm formuliert. In der Archäologie des Wissens, dem Werk, das als sein «Methodenbuch» angesehen wird, stellt er fest, dass Diskurse sich durch bestimmte Regelmäßigkeiten auszeichnen, die der Diskursanalytiker zu erfassen hat. Typen von Regelmäßigkeiten sind die «Formationsregeln der Gegenstände» (wie die Gegenstände konstituiert werden), die «Äußerungsmodalitäten» (Sprecherpositionen), die «Begriffe» oder «Begriffsformationen» und die «strategische Wahl» (Foucault 1981, 94104). 
In der vorliegenden Analyse beziehe ich mich vor allem auf die «Begriffe» und die «strategische Wahl». Die Begriffe werden auf die ihnen zugeordneten Bedeutung hin untersucht. Diese ist niemals objektivierbar und statisch, sondern entspricht, wie Busse in seinen Überlegungen zur Erweiterung der historischen Semantik feststellt, einer Vielzahl von «konkreten Verwendungsmöglichkeiten» (Busse 1987, 115). Untersuchungen, die den «Begriff» zum Objekt der Analyse machen, entsprechen daher einer Sammlung von Momenten, die mit der Verwendung eines Zeichens in Zusammenhang stehen (Busse 1987, 82 s., 304). Sie können niemals losgelöst von ihrem Umfeld und von ihrer Rolle im Argumentationszusammenhang untersucht werden. Die Analyse der Argumentationsmuster des Diskurses, die unter das fällt, was Foucault die «strategische Wahl» nennt (Link 1999, 151), kann daher als Ergänzung der Begriffsanalyse gelten (cf. Niehr/Böke 2003 und Böke et al. 2000). ${ }^{1}$

Vorliegender Analyse liegen die Begriffe «Sprache», «Identität» und «Nation» zugrunde. Diese wurden ausgewählt, da sie als das gelten können, was Jürgen Link «diskurstragende Kategorien» nennt:

«Diskurstragende Kategorien sind solche, durch deren «Entfernung wenn man sie sozusagen aus dem betreffenden Diskurs 〈herauszöge〉 wie die Stahlteile aus einer Betonkonstruktion - der betreffende Diskurs nicht länger 〈halten〉 könnte und in sich zusammenbräche wie ein Kartenhaus» (Link 1997,15).

Die Argumentationsmuster des analysierten Diskurses setzen die genannten Begriffe in ganz bestimmter Weise zueinander in Beziehung. ${ }^{2}$ Diese Beziehung wird auch in weiteren für den Diskurs zentralen Begriffen ausgedrückt: «llengua pròpia», «Normalisierung» und «Kollektive Sprachrechte». Alle wurden darauf hin untersucht, welche Bedeutung ihnen in verschiedenen Verwendungskontexten zugeordnet wird und welche Relevanz und welchen Zweck diese Bedeutungszuschreibung innerhalb der Argumentationsmuster hat.

${ }^{1}$ Diese Gruppe von Sprachwissenschaftlern entwickelte den sogenannten «Düsseldorfer Ansatz», der die Diskursanalyse im Rahmen einer «mentalitätsgeschichtlichen Sprachgeschichtsschreibung» fruchtbar machen will. Dieser schlägt eine Kombination der Analyse zentraler Begriffe und zentraler Argumente vor. Man könne so idealerweise auch Aussagen darüber machen, «mit welchen materiell-sprachlichen Mitteln bestimmte Argumentationsmuster bevorzugt realisiert werden, wie also Argumentationsmuster möglicherweise gemeinsam mit bestimmten Schlüsselwörtern oder Metaphern Wirklichkeit konstruieren oder wie die wirklichkeitskonstitutive Leistung von Schlüsselwörtern erst im Rahmen ihrer Funktion in Argumentationszusammenhängen angemessen erfasst werden kann» (Böke et al. 2000, 26).

${ }^{2}$ Die gewählten Begriffe erfüllen zudem die von Niehr/Böke für die «Diskursrelevanz» eingeführten Kriterien: häufiges Vorkommen, sprachliche Heterogenität bzw. Konkurrenz, metasprachliche Thematisierung und Sprachwandel (Niehr/Böke 2003, 329). 


\section{Diskursanalyse und Sprachwissenschaft}

Der Gegenstand der Sprachwissenschaft, die Sprache, ist in zweifacher Weise in den Komplex dessen, was als Diskurs bezeichnet wird, einbezogen. Sie ist das Instrument, über das sich Diskurse und Wirklichkeitsinterpretationen konstituieren und verbreiten, sie ist jedoch zugleich auch selbst Gegenstand dieser Diskurse, wenn darüber geredet wird, was Sprache ist oder wie gesprochen werden sollte. Der Diskurs über Sprache schafft Sprachbewusstsein bzw., wie bereits Brigitte Schlieben-Lange feststellte, Sprachbewusstsein ist «Diskurs über Sprache» (Schlieben-Lange 1991, 109). Dieser Diskurs oder dieses Bewusstsein ist insofern wirklichkeitskonstituierend, als dass er darauf einwirkt, wie letztendlich tatsächlich gesprochen wird: die gesprochene Sprache selbst ist somit eine der Wirklichkeiten, die vom Diskurs hergestellt werden.

Definiert man Sprachpolitik als den Versuch, auf Sprachbewusstsein und somit Sprechpraktiken einzuwirken, dann kommt eine sprachwissenschaftliche Theorie, die sich mit Sprachpolitik beschäftigt, um eine Behandlung von Diskursen kaum herum. Dies hat in der Romanistik auch die Leipziger Forschungsgruppe Soziolinguistik in ihrem Versuch, eine «Theorie der Sprachpolitik» zu formulieren, erkannt (Bochmann et al. 1993, 5s.). Metasprachliche Diskurse (also das Sprechen über Sprache) werden hier als zentrales Instrument von Sprachpolitik, und somit auch als zentraler Untersuchungsgegenstand der Theorie der Sprachpolitik betrachtet (Bochmann et al. 1993, 58$62)$.

Man könnte also auch sagen: insbesondere all das, was über Sprachen (und Dialekte) gesagt wird, ist Bestandteil eines sprachpolitischen Diskurse, insofern es auf das Denken über diese und somit auf die Sprechpraxis einwirkt.

\section{Sprachnationalismus}

Da die Sprachwissenschaft der Ort des Redens und Denkens über Sprache per se ist, ist es besonders interessant zu untersuchen, welche Diskurse hier über die Sprache und ihre Verknüpfung mit Nation und nationaler Identität produziert wurden und werden. ${ }^{3}$

\footnotetext{
3 «Nation» verwende ich hier im Sinne einer «vorgestellten Gemeinschaft» (Anderson), die meint, sich in bestimmter Weise (durch Sprache, Kultur, Mentalität, Bewusstsein etc.) von anderen Gemeinschaften zu unterscheiden und die diese Unterscheidung durch eine gewisse politische Selbstbestimmung unterstreichen möchte. Die Frage, was genau in einer Nation als Differenz- und Abgrenzungsmerkmal gilt, und auch die politischen Forderungen, die sich daraus ableiten, sind unterschiedlich. «Realität» besitzt die Nation in dem Sinne, wie sie in dem Bewusstsein der Menschen vorhanden ist. Dazu ein Zitat von Ruth Wodak: «Wenn eine Nation eine vorgestellte Gemeinschaft, mithin ein mentales Konstrukt, ein imaginärer Vorstellungskomplex ist, der - zumindest - die Bestimmungselemente der kollektiven Einheit und Gleich-
} 
Im folgenden sollen die zentralen Gedanken dreier Sprachwissenschaftler zu diesem Thema dargestellt werden. Diese werden uns zu den zentralen Eigenschaften einer Diskurstradition führen, die ich nach Gardt (1999) «Sprachnationalismus» nennen will und die als Grundlage für die Analyse des aktuellen katalanischen Diskurses genutzt werden kann.

Andreas Gardt (1999) macht drei Kennzeichen des Sprachnationalismus aus. ${ }^{4}$ Als erste Eigenschaft nennt er:

«Das emphatische Lob der eigenen Sprache und zugleich ihre Vergegenständlichung, d.h. Hypostasierung zu einer Größe jenseits historischer und sozialer Bezüge; dieser Größe wird eine von den Sprechern irgendwie unabhängige Natur (Charakter, Wesen, Kraft, Geist, Genie/Genius) zuerkannt [...]; als ihre charakteristischen Eigenschaften gelten: hohes Alter, genealogische Reinheit und strukturelle Homogenität [...]» (Gardt 1999, 91 s., Kursiv im Original).

Damit wird die Ansicht des Sprachnationalismus darüber, was Sprache ist, formuliert. Ich will diese Ansicht im Folgenden als Vergegenständlichung (Hypostasierung) bezeichnen. Sie unterteilt sich in vier Aspekte: (a) die Ansicht, die Sprache sei eine eigenständige Entität, die, wie Gardt später spezifiziert, «dem Menschen [...] gegenübertritt, die auf sein Denken, Fühlen und Handeln Einfluß zu nehmen vermag» (Gardt 1999, 93), und die (b) nicht als durch historische und soziale Einflüsse Entstandenes, sondern als etwas von Natur aus Existentes bzw. Schon-immer-da-Gewesenes erscheint (Gardt verweist später auf die zu Beginn der Aufklärung übliche Behauptung, das Deutsche sei schon beim Turmbau zu Babel entstanden; Gardt 1999, 93). Diese Eigenschaften müssen automatisch zu den Annahmen führen, Sprache sei (c) etwas Homogenes, also eine klar definierbare, abgrenzbare Einheit ohne Variationen und (d) etwas Statisches, Unveränderbares, also durch gesellschaftliche und historische Umstände nicht Beeinflussbares. Dabei ist, so möchte ich zu diesem letzten Punkt hinzufügen, das Wissen, dass Sprache sich verän-

heit, der Begrenzung und Autonomie enthält, dann kommt dieser Imagination soweit Realität $\mathrm{zu}$, wie man von ihr überzeugt ist, wie man beziehungsweise an sie glaubt und sich emotional mit ihr identifiziert. Die Frage, wie diese Vorstellung in die Köpfe derer gelangt, die von ihr überzeugt sind, lässt sich leicht beantworten: Sie wird diskursiv konstruiert und in Diskursen vermittelt, und zwar in erster Linie in Erzählungen der Nationalkultur. Die nationale Identität ist somit das Produkt von Diskursen» (Wodak 1998, 61). Das gleiche gilt auch für die Begriffe «nationale Identität», aber auch für «Volk», «Ethnie» oder «Ethnizität».

${ }^{4}$ Andreas Gardt hat in einer wissenschaftsgeschichtlichen Aufarbeitung aufgezeigt, wie sich eine von ihm als «Sprachnationalismus» identifizierte Ideologie wie ein roter Faden durch die Geschichte der deutschen Sprachwissenschaft, Sprachpflege und Sprachkritik zieht. Er bezieht sich dabei auf Texte aus verschiedenen Jahrhunderten, auch aus der Zeit vor 1800, selbst wenn dort von «Nationalismus» im Sinne von Staatsnationalismus noch nicht die Rede sein kann: Nationalismus verstanden als «Nationalbewusstein», so Gardt, sei jedoch auch schon für die Frühe Neuzeit, gar das Mittelalter belegt und zudem setze Nationalismus nicht die Existenz einer Nation voraus, sondern bringe diese umgekehrt erst hervor (Gardt 1999, 90s.). 
dern kann, durchaus existent. Solch eine Veränderung impliziert jedoch im sprachnationalistischen Denken, dass die Identität der Sprache korrumpiert wird und diese somit, nicht mehr die Gleiche seiend, zu etwas anderem, als «falsch» Empfundenen mutiert.

Die Hypostasierung von Sprache besteht also in der Zuordnung von Eigenständigkeit, Naturgegebenheit, Homogenität und Statik. Im gleichen Sinne werden im Sprachnationalismus auch die Begriffe «Nation» und «Identität» hypostasiert, um sodann alle drei miteinander in Beziehung zu setzen. Über diese Beziehung können Punkt zwei und drei in Gardts Charakterisierung des Sprachnationalismus aufklären:

«2. das Übereinanderblenden [...] der Bereiche des Sprachlichen mit denen des Kulturell-Ethnischen (Sprache-Volk/Kultur/Nation etc., mit dem Sonderfall des Ethisch-Moralischen: Sprache-Sitte/Moral etc.), des Politischen (Sprache, Nation, Reich, Land etc.), in Teilen auch des Anthropologischen (Sprache-Stamm, Rasse/Volk, ...); Resultat dieses Übereinanderblendens ist die Identifizierung eines Sprachcharakters (bzw. einer Sprachnatur, eines Sprachwesens etc.) mit einem Volks- oder $\mathrm{Na-}$ tionalcharakter.

[...]

3. die pointiert bis aggressiv formulierte Behauptung der Überlegenheit der eigenen Sprache und damit, aufgrund des erwähnten Übereinanderblendens, der eigenen kulturell-ethnischen (oder ethisch-moralischen), anthropologischen und politischen Gemeinschaft über andere Gemeinschaften sowie (implizit oder explizit) die Behauptung der Gefährdung der Integrität bzw. Identität der eigenen Sprach-, Volks- und Kulturgemeinschaft durch fremde Sprachen, Völker, Rassen, Nationen und Kulturen; als Folge dieser Behauptungen die z. T. aggressive Abwertung des sprachlich (und zugleich kulturell-ethnisch, anthropologisch und politisch) Fremden» (Gardt 1999, 92, Kursiv im Original).

Es sei vorwegzunehmen, dass folgende der hier von Gardt angeführten Punkte aus der hier zu erarbeitenden Definition des Sprachnationalismus ausgeblendet werden, da diese im katalanischen Kontext keine Bedeutung haben: ${ }^{5}$ es wird nicht die Rede der Sprache als Ausdruck von «Rasse» sein und auch nicht von «Sitte» und «Moral». Ebenso werden keine Aussagen über bestimmte Wesenszüge der Sprache gemacht, die gleichzeitig auch dem Volke zugeordnet werden und demnach auch keine Aussagen zur Überlegenheit der eigenen Sprache und zu der daraus abgeleiteten Überlegenheit des eigenen Volkes und Abwertung des Fremden. In dem hier skizzierten Zusammenhang ist aus Gardts Ausführung zunächst nur der Gedanke des Übereinanderblendens von Sprache-Volk/Kultur/Nation und «die Identifizierung eines Sprachcharakters [...] mit einem Volks- oder Nationalcharakter» (Gardt 1999, 92) herauszugreifen. Ausgangspunkt dieses Kerns sprachnationalistischer Überle-

\footnotetext{
${ }^{5}$ Dies ist v.a. der Tatsache zu zollen, dass sich der katalanische nicht als ethnischer, sondern als «kultureller» Nationalismus versteht. $\mathrm{Zu}$ den Schwierigkeiten, die dies mit sich bringt, und der daraus resultierenden Überbetonung des Faktors «Sprache» cf. weiter unten.
} 
gungen ist, wie Gardt später darlegt, die These, dass die Strukturen jeder Sprache die Sprecher die Welt auf eine bestimmte Art erkennen ließen, so dass jede Einzelsprache eine besondere Weltsicht hervorbringe. Diese These tritt nicht nur bei Herder und Humboldt (Weltbildthese) auf, sondern auch bei etlichen Sprachwissenschaftlern des 19. Jh. (Gardt 1999, 104), bis sie schließlich in Benjamin Lee Whorfs These der sprachlichen Relativität ihre vielleicht extremste Ausprägung erhielt.

Die These allein, dass Sprache Kultur widerspiegele, ist jedoch nicht als ideologisch anzusehen (Gardt 1999, 104). ${ }^{6}$ Sie hat jedoch m. E. eine grundlegende sprachnationalistische Vorstellung erst ermöglicht: nämlich die, jedes «Volk» habe eine bestimmte, klar abgrenzbare, eigentümliche Sprache hervorgebracht bzw. umgekehrt (welches Element das Determinierende ist, bleibt meist im Dunkeln): die Sprache habe durch ihr Wesen einen bestimmten Volkscharakter und somit eine klar abgrenzbare Volksgemeinschaft, deren Mitglieder die gleiche Weltsicht teilen, hervorgebracht und diese Volksgemeinschaft konstituiere daher eine Nation. Mit anderen Worten: Die «Weltbildthese» kann in ihren verschiedenen Ausprägungen dankbar von einem Nationalismus aufgenommen werden, der Nationen über Sprache zu definieren sucht, der also behauptet: Nationen sind nach außen hin klar abgrenzbare und nach innen hin homogene Sprachgemeinschaften. ${ }^{7}$

Zum Sprachnationalismus will ich daher im Folgenden auch die Idee zählen, dass die Beziehung zwischen Sprache und Nation eine ausschließliche sei, d.h. jeder Nation könne nur eine Sprache zugeordnet werden. Ich möchte diese Vorstellung im Folgenden - da sie eine einseitige Beziehung zwischen Sprache und Nation charakterisiert - Eindimensionalität nennen. Zu dieser tritt zudem die Vorstellung der Unveränderbarkeit dieser Beziehung: die Auffassung, dass jeder Nation für alle Zeiten die gleiche Sprache zuzuordnen sei.

Aus der Idee einer eindimensionalen und unveränderbaren Beziehung zwischen Sprache und Nation ergibt sich sodann automatisch die bei Gardt in Punkt drei genannte «Behauptung der Gefährdung der Integrität bzw. Identität der eigenen Sprach-, Volks- und Kulturgemeinschaft durch fremde Sprachen, Völker, Rassen, Nationen und Kulturen»(Gardt 1999, 92). Greift man hier lediglich die Verbindung zwischen Sprache und Nation heraus, ist zu sagen, dass es nicht weiter verwunderlich ist, dass eine Nation, die sich als Sprachgemeinschaft definiert, bedroht erscheint, wenn ihre Sprache es ist. Die Nation steht und fällt in dieser Logik mit der Bewahrung der Möglichkeit, sie durch

${ }^{6}$ Gardt definiert sie erst dann als solche, wenn daraus eine Hierarchisierung der Sprachen (z. B. sie sei zum Ausdruck des Denkens besser geeignet) entwickelt wird, die gemäß dem Übereinanderblenden auf eine Hierarchisierung der Völker/Kulturen/ Nationen/Rassen hinauslaufe (Gardt 1999, 104s.).

7 Die Idee der homogenen Sprachgemeinschaft als Stütze der Nationenbildung und des Nationalismus hat Benedict Anderson in seinem Werk Imagined Communities (1981) ausführlich dargelegt. 
Sprache zu identifizieren. Diese Idee will ich im folgenden Schicksalsverknüpfung nennen.

Hier können wir nun an die Überlegungen Blommaerts anschließen: Dieser sucht und findet sprachideologische Auffassungen nicht wie Gardt in der zeitlich weit zurück liegenden Geschichte der Sprachwissenschaft, sondern in der «traditionellen» Literatur zur Sprachplanung. ${ }^{8}$ In Bezug auf ein Zitat von Edmun Richmond von 1993, das die Sprachenvielfalt Afrikas als Problem für die Nationenbildung ansieht, erklärt Blommaert das, was er den «one-language-one-culture-view» nennt:

«A first observation that can be made is that Richmond (like many others), uses language and ethnicity in an almost fixed collocation, and so adopts a complex set of assumptions about these matters which can be summarized as follows: linguistic differences are ethnic differences; language marks ethnicity; language always indexes emotions attached to one's ethnicity; multi-ethnolingualism is therefore an obstacle to nation building [...]» (Blommaert 1996, 10s., Hervorhebungen vom Autor).

Die Mehrsprachigkeit einer Nation gilt als anormal, und dies ist so, weil Sprachen als Indiz für die Differenz zwischen «Ethnien» gelten und diese Differenz in dem Bild einer «homogenen» Nation keinen Platz hat. ${ }^{9} \mathrm{Zu}$ der Beziehung Nation-Sprache tritt über die Thematisierung der Ethnizität und der Zugehörigkeit jedes Einzelnen zu dieser nun noch eine dritte Komponente hinzu: das Individuum.

«At another level, it is assumed, that every individual has one and only one ethnolinguistic identity: $\mathrm{s} / \mathrm{he}$ speaks one language (the mother tongue), and has therefore only one ethnic identity. [...] The basic permise underlying Richmond's view is that people are intrinsically monolingual and mono-ethnic, all 〈multi's〉 come afterwards, as a product of an abnormal and distorted development» (Blommaert 1996, 10s., Hervorhebungen vom Autor).

Blommaert sieht hier eine Verbindung zwischen der Vorstellung des einsprachigen Individuums mit der des «ethnisch» eindeutig definierbaren Individu-

8 Mit «traditionell» meint Blommaert anscheinend eine konservative Sichtweise des Zusammenhanges zwischen Sprache und Nation, nicht so sehr eine zeitlich zurück liegende Strömung, denn das Zitat, das ihm als Exempel dient, stammt von 1993. Als «traditionelle Sichtweise» identifiziert übrigens auch Blommaert zunächst die Vergegenständlichung von Sprache, er spricht von «organic views of languages» und erklärt: «The languages seem just to be <out there〉, their number, character, and status being, so it appears, gifts of nature» (Blommaert 1996, 10).

${ }^{9}$ Ich hatte oben bemerkt, dass von «Rasse» im katalanischen Kontext nicht die Rede sein wird (cf. n. 5). In anderen Kontexten hat der Begriff der «Ethnie» jenen relativ nahtlos ersetzt. Obwohl hiermit oft die Bedeutung kultureller Unterschiede betont werden soll, spielt auch hier meist die Vorstellung einer irgendwie (nicht genau spezifizierten) angeborenen Unterscheidung zwischen den Völkern durchaus eine Rolle. Was genau mit dem Begriff gemeint ist, wird verständlicherweise daher meist im Dunkeln gelassen. 
ums (daher spricht er von «ethnolinguistischer Identität»). Die Annahme, Individuen sei immer nur eine Sprache als originäre, quasi angeborene eigen, ist tatsächlich immer mit der Idee verbunden, die Identität des Individuums speise sich einzig und allein aus der Zuordnung zu nur einer Gruppe, sei diese definiert als «Ethnie», «Volk» oder «Nation». ${ }^{10}$

Hier kommt nun die Studie von Claus Ahlzweig ins Spiel: Er zeichnet die Geschichte des Wortes «Muttersprache» und seinen Eingang in die deutsche Sprachwissenschaft nach. Ab der Zeit des Wilhelminismus werde, so Ahlzweig, der Begriff dazu benutzt, die «Eigenschaften der deutschen Sprache zu ahistorischen Wesensmerkmalen des deutschen Menschen» zu machen. Durch diese Behauptung (aus der Sprache ließen sich Wesensmerkmale ableiten), verbunden mit der Annahme, jeder einzelne sei mit seiner Muttersprache (und somit diesen Wesensmerkmalen) unauflösbar verwachsen, wird das Individuum untrennbar an die Sprach- und somit (Wesensmerkmals-) und Volksgemeinschaft gebunden. Als «Muttersprache» gilt dabei automatisch die Standardsprache der Nation, so dass die Bindung des Individuums an diese sicher gestellt wird. Dies wird in einem von Ahlzweig angeführten Zitat des deutschen Sprachwissenschaftlers Leo Weisgerber deutlich:

«Das Gesetz der Muttersprache sichert einen Vorrang von unermesslicher Tragweite, dass nämlich der junge Mensch der Gemeinschaft, in die er hineingeboren ist, auch geistig eingegliedert wird. Erlernen der Muttersprache besagt ja nicht, dass das Kind nun Bezeichnungen und Ausdrucksformen übernähme, die ihm als solche bereits angeboren oder auf anderem Wege zugänglich wären. Sondern mit der Muttersprache eröffnet die Gemeinschaft dem Nachkommenden das Tor zur geistigen Welt ihres Volkes [...]. Andererseits wird dem Menschen diese sprachliche Zwischenwelt so tief eingeprägt, dass er aus ihrem Bann gar nicht mehr herauskann, die Begriffe und Denkformen seiner Muttersprache werden ihm 〈selbstverständlich〉, er bewegt sich so vollkommen in ihren Bahnen, dass er ihren sprachlichen Charakter überhaupt nicht mehr ahnt, sondern sie als einfache Wirklichkeit, als unmittelbare Entsprechung des tatsächlich Seienden nimmt. Diesen Weg gehen alle Menschen in ihre Jugend; alle, die der gleichen Muttersprache angehören, werden in das Weltbild dieser Sprache und der sie tragenden Gemeinschaft eingegliedert» (Weisgerber 1941, 4s.).

Ahlzweig kommentiert:

«In dieser argumentativen Setzung erscheinen die zentralen Ideologeme von der Muttersprache als gemeinschaftsstiftender Kraft, die eine alle Deutschen verbindende sprachliche Weltsicht allen Deutschen aufzwingt. Diese Auffassung teilt Weisgerber mit vielen anderen Sprachwissenschaftlern seiner Zeit» (Ahlzweig 1994, 187).

${ }^{10}$ Die soziale Identität eines Individuums bildet sich über soziale Prozesse und somit über seine Zugehörigkeit zu verschiedenen Gruppen (cf. Oppenrieder/Thurmair 2003, 40s.). Man könnte also sagen, dass nationalistische Denkweisen die Identität als aus nur einer (oder als wichtigste angesehenen) Gruppenzugehörigkeit heraus definieren: aus der zur nationalen Gemeinschaft. 
So möchte ich als weiteren Aspekt zur Definition von Sprachnationalismus hinzufügen: Von «Muttersprache» oder auch «Sprachidentität» ist hier zu einem bestimmten Zwecke die Rede, nämlich dem, die unlösbare Anbindung des Individuums an die Sprachgemeinschaft zu beweisen und zu sichern. Da diese Sprachgemeinschaft im Sprachnationalismus der Nation entspricht, wird das Individuum über die Sprache an die Nation gebunden. Die Sprachidentität ist somit - auch gemäß dem von Gardt identifizierten Usus des «Übereinanderblendens» - nichts anderes als die Nationalidentität.

Da die Beziehung zwischen Sprache und dem Individuum sich aus dessen Zugehörigkeit zu einer Nation erklärt, weist sie die gleichen Charakteristika auf, wie die zwischen Sprache und Nation: sie ist eindimensional und unveränderbar. Auch die Schicksalsverknüpfung ist vorhanden, denn die (nationale) Identität steht und fällt mit der Bewahrung der (National-/Mutter-)Sprache. Die Übernahme einer fremden Sprache wird als Identitätsverlust verstanden.

Zusammenfassend kann gesagt werden, dass alle drei Begriffe, «Sprache», «Nation» und (nationale, und nur von dieser ist hier die Rede) «Identität», in einem Diskurs, den ich «Sprachnationalismus» nenne, eine Hypostasierung erfahren, so dass ihnen Eigenständigkeit, Naturgegebenheit, Homogenität und Statik nachgesagt werden. Die Beziehung zwischen den drei Entitäten charakterisiert sich durch Eindimensionalität und Statik. Daher kommt es zwischen ihnen zu einer unauflösbaren Schicksalsverknüpfung.

\title{
5. Sprachpolitischer Diskurs in Katalonien
}

\subsection{Hypostasierung von Sprache}

\begin{abstract}
«Doncs bé, la identitat de Catalunya és en gran part lingüística i cultural. Mai la reivindicació de Catalunya no ha estat étnica ni religiosa ni ha fet lleva en la geografia ni ha estat estrictament política. Hi ha molt components en la nostra identitat, n'hi ha una pila, però la llengua i la cultura en són l'espina dorsal. Per tant, si la llengua i la cultura fossin greument afectades la personalitat de Catalunya ho seria també» (Pujol 22. 03. 05, 175).
\end{abstract}

Um die «identitat de Catalunya», die Existenz von Katalonien als von anderen Regionen abgrenzbare Nation, mit Inhalten versehen zu können, muss der katalanische Nationalismus - so wie in diesem Zitat von Pujol - auf eine eigene «Sprache» und eine eigene «Kultur» verweisen (von einer ethnischen Definition sieht der katalanische Nationalismus ab). Der Inhalt der katalanischen «Kultur» ist aufgrund der Nähe zur spanischen, um nicht zu sagen zu allen europäischen Kulturen schwer zu benennen. Außer einigen angeblichen und nicht unbedingt «besonderen» Eigenschaften der katalanischen Mentalität ${ }^{11}$

11 Topoi, die in der volksüblichen Definition des «katalanischen Seins» genannt werden, sind: Sinn für Demokratie, «europäischer» Charakter, Fleiß, Kreativität, Selbstverantwortung. Sie sind auch in einzelnen verstreuten Aussagen in Pujols Reden wieder zu finden. 
und einigen folkloristischen Verweisen auf katalanische Bräuche und Tänze bleibt daher die Sprache ihr einzig greifbarer Inhalt. Dies erklärt ihren hohen Stellenwert im nationalistischen Diskurs Kataloniens.

Solch ein Diskurs, der Sprache als konstituierendes Grundelement von Nation definieren möchte bzw. muss, kann diese niemals als durch die Sprechhandlungen der Sprecher sich wandelnd begreifen, sonder nur als statische, durch sich selbst bestehende Größe. Diese Hypostasierung von Sprache wird nicht explizit thematisiert, sondern ist verschwiegene Voraussetzung für die Argumentation des Zusammenhangs zwischen Sprache, Nation und Identität. Ich möchte hier als «Beweis» lediglich auf Pujols Sprachgebrauch der Begriffe «lengua» und «catalán» verweisen. «La llengua» ist meist personifiziertes Subjekt, und dies meist von Verben, die dem semantischem Wortfeld «stützen» oder «geben» zuzuordnen sind:

«[...] la llengua dóna personalitat pròpia a Catalunya» (Pujol 22.3.95, $181)$.

«[...] la llengua catalana: la que de fet li [a Catalunya] donava consistència i que podia continuar mantenint la personalitat pròpia del país que tots els habitants necessitem per a nosaltres i les nostres fills» (Pujol 20.3.95, 168).

Die Sprache ist immer dem Bild der Stütze und der Basis zugeordnet, was auch durch Epitheta wie «bàsic», «determinant» und «fonamental» («és un signe bàsic d'identitat, un element determinant de la seva personalitat»; Pujol 22.3.95, 175) ausgedrückt wird. Die Sprache hat also Eigenständigkeit, sie ist eine Kraft, die, wie Gardt sagt, «dem Menschen [...] gegenübertritt» (Gardt 1999, 93) und die Nation und die Sprecher stützt, anstatt umgekehrt durch diese geformt und erhalten zu werden. Die ihr zugeordneten Metaphern suggerieren die Vorstellung, sie sei etwas Naturgegebenes, denn sie stammen aus dem Bereich der «Körperteile»: «espina dorsal de la nostra identitat» (Pujol 22.3.95, 175), «llengua medul-lar» (Pujol, 22.3.95, 179), «nervi de nostra nació» (Pujol 22.3.95, 174) oder «fibra interior forta [de Catalunya]» (Pujol 22.3.95, 193). Diese Sichtweise von Sprache als Stütze und Basis, als grundlegender Bestandteil eines Körpers, als naturgegebene Entität, impliziert sowohl ihre Statik als auch ihre Homogenität. Solch eine Hypostasierung von Sprache ist stillschweigende Grundbedingung eines Diskurses, der ihr eine eindimensionale und unveränderbare Beziehung zu Nation und Identität bescheinigen will.

\subsection{Sprache und Nation}

Wie oben festgestellt, ist der katalanische Nationalismus darauf angewiesen, Sprache als wichtigste Determinante von Nation anzusehen. Allein Pujols Rede vom 22.03.05 könnten etliche Zitate entnommen werden, die darauf verweisen. Ich zitiere den Beginn der Rede: 
«Els he convidat a aquesta conferència, i els agradeixo molt que hagin vingut, perquè crec que per a Catalunya la llengua, la llengua catalana, és un element bàsic de la nostra identitat, del nostre ésser com a poble. He dit algun cop, emprant la fórmula d'un filòleg basc, que el català és el nervi de nostra nació» (Pujol 22.03.95, 174).

Die Beziehung zwischen Nation und Sprache ist hier zunächst etwas, an das Pujol nur «glaubt» («crec que»). Im nächsten Satz bezieht er sich auf eine Autorität aus den Wissenschaften («filòleg basc»), um den Wahrheitscharakter seiner Äußerung zu untermauern. Ab diesem Zeitpunkt wird in dieser Rede von der Beziehung immer nur noch als Tatsache gesprochen, die nicht mehr hinterfragt werden muss, z.B. «la llengua és un signe bàsic d'identitat, un element determinant de la seva [des Volkes, K.S.] personalitat» (Pujol 22.03. 05, 175). Durch diese Strategie erscheint die Beziehung dem Leser/Hörer schon bald als naturgegeben und unhinterfragbar.

Da die Nation dadurch quasi als durch Sprache konstituiert definiert wird, ist beider Schicksal miteinander verknüpft, wie ja auch schon die eingangs zitierte Äußerung zur Identität Kataloniens zeigte: «Per tant, si la llengua i la cultura fossin greument afectades la personalitat de Catalunya ho seria també» (Pujol 22.03.05, 175). Pujol verweist in der Rede wiederholt auf eine «jahrhundertlange Verfolgung» der Sprache:

«[La persecució que la llengua i la cultura catalanes han sofert] no ha estat un fet fugaç i superficial com a voltes ens volen fer creure. Ha estat una persecució de segles, sempre feta molt a fons, amb voluntat de destrucció [...]. No es pot treure importància a una persecució que comença a l'any 1714 i que dura fins al 1975, amb breus, escasses i mai completes interrupcions» (Pujol 22.3.95, 180). ${ }^{12}$

Diese vergangene Verfolgung der Sprache und die Gefahr, der sie auch noch aktuell ausgesetzt ist, ist Beweis dessen, dass auch die Nation Katalonien in ihrer Existenz bedroht ist. Am eindrücklichsten schildert Pujol die Abhängigkeit der Nation von der Sprache in dem Bild eines Körpers, der zusammenbricht, wenn seine Basis fehlt:

12 Eine «jahrhundertlange» Verfolgung des Katalanischen zu konstatieren, ist unangemessen. Das vom zentralistischen König Felipe de Anjou im 18. Jh. erlassene Decreto de Nueva Planta, das erstmals das Spanische zur Amtssprache in Katalonien deklarierte, war letztendlich nur noch eine reine Formsache, denn das Katalanische war ohnehin bereits lediglich in mündlicher Form lebendig geblieben (Mar-Molinero 2000, 42). Nur die Behandlung des Katalanischen unter Primo der Rivera und Franco kann als Repression aufgefasst werden, da hier die Nutzung des Katalanischen im öffentlichen Raum verboten wurde. Es handelt sich jedoch jeweils um relativ kurze Zeitabschnitte, nicht um «jahrhundertlange Verfolgungen». Kurz nach dem Zweiten Weltkrieg wurden so die harten Sprachgesetze des Francoregimes wieder gelockert. Bereits in den 40er Jahren wurden wieder katalanische Bücher publiziert, Theatervorstellungen und Zeitschriften auf Katalanisch zugelassen (Schmidt-Felzmann 2001, 156). Ab 1960 wurde die kulturelle Produktion in katalanischer Sprache wieder belebt (Bauernschmidt 1999, 44, Bochmann et al. 1993, 434). 
«Que el catalán sea el centro de este modelo de bilingüismo». Vostès ja saben com es definineix el centre de gravetat: és el un punt d'un cos on es concentra el pes d'aquest cos. I ja saben, si el centre de gravetat és situa fora de la base de sustentació, el cos cau. És a dir, el respecte al centre de gravetat és la garantia d'estabilitat i de viabilitat» (Pujol 22. 03.95, 179).

Vergangene und aktuelle Bedrohung der Sprache und somit der Nation sind sodann die Grundlage, auf der im Diskurs ein «Kampf» angesagt wird, zu dem alle Katalanen, die sich als solche begreifen, aufgerufen sind. Zur Waffe dieses Kampfes wird das Sprechen erklärt, die «militància equilibrada i ponderada en favor del català» (Pujol 22.3.95, 193). Die Sprecher sind sozusagen dazu aufgerufen, durch das Sprechen die Konturen der Nation zu wahren:

«El català és també una eina de treball i un instrument de promoció. Però apart d'això, tothom que vulgui que Catalunya conservi una fibra interior forta i una personalitat pròpia i ben definida ha d'entendre que el català hi té un paper essencial i imprescindible. I tothom ha d'entendre també això, és a dir, disposar d'un país cohesionat i amb personalitat, és bo per a tothom, és necessari» (Pujol 22.3.95, 193).

Weniger bildhaft und eindrücklich als in den rhetorisch wirksamen Reden Pujols ist die Behauptung des Zusammenhanges zwischen Sprache und Nation bei den katalanischen Sprachwissenschaftlern. Gerade jedoch die Tatsache, dass Aussagen darüber hier eher sachlich behandelt werden und als wissenschaftliche Feststellungen in Erscheinung treten, verleiht ihnen besonderes Gewicht. Dass Sprache die Stütze der Nation ist, wird hier sozusagen einfach nur konstatiert, die Frage nach dem Warum gar nicht mehr gestellt. Nur zwei Beispiele seien genannt:

Der bekannte Soziolinguist Antoni María Badia i Margarit hielt 1986 eine Rede auf einer Konferenz der Academia de la Llingua Asturiana mit dem Titel «Llengua e identitat nacional». Er formuliert hier zwei Thesen zum Verhältnis zwischen Sprache und Nation:

«a) La llengua vertebra la nació». A l'origen, la llengua separa, després aglutina i singularitza [...]

b) Al seu torn, i com a segona formulació, 〈a nació s'explica, es fa, es realitza i es defensa mitjançant la llengua. Podrém citar- ne nombrosos examples. La nació és coneguda per un conjunt de característiques que abans hem anomenat <elements de cohesió> [...]: una cultura, una literatura escrita, una tradició, un dret consetudinari, una història comuna, i, sobretot, per la llengua en què tots aquests elements s'expressen» (Badia i Margarit 1988, 15). ${ }^{13}$

${ }^{13}$ Zwar thematisiert Badia i Margarit, dass seine Thesen nicht immer zuträfen, denn Sprache sei nicht immer ein Merkmal, das Nationen einzigartig erscheinen lasse («La llengua no sempre singularitza», als Beispiel nennt der die Länder Lateinamerikas, Badia i Margarit 1988, 15), und umgekehrt einer Nation auch nicht immer nur eine Sprache zuzuordnen sei («la nació no sempre s'explica mitjançant la llengua, ja que, de vegades correspon a més d'una llengua», als Beispiel nennt der die Schweiz, Badia i Margarit 1988, 16), jedoch schmälert dies ja nicht die Tatsache, dass er oben 
Zwar sieht Badia i Margarit den Zusammenhang zwischen Sprache und Nation als historisch gewachsen an, verharrt jedoch gerade dadurch in dem Widerspruch, dass er gleichzeitig für die (Wieder)Verbreitung der Sprache in einem nationalen Territorium plädiert, deren Nicht-Mehr-Bindung an dieses ja gerade von einer historischen Auseinanderentwicklung zeugt, anstatt eine unlösbare Gemeinschaft beider zu beweisen.

Auch Joaquin Arenas Sampera, Sprachwissenschaftler, Pädagoge und von 1983 bis 2003 Direktor des dem Erziehungsministerium unterstehenden Servei d'Ensenyament del Català (SEDEC), sieht die Sprache als grundlegenden Definitionsfaktor für Nationen an. In seinen «Assaigs contemporanis» von 1991 schreibt er:

«La llengua, així de clar, és una, la pròpia del país; les altres s'han de conéixer i dominar però no poden suplantar el factor idiomàtic que és el nervi de la nació i que infon una determinada manera de ser i actuar [...]» (Arenas 1991, 78).

Dass die eindimensionale Verbindung von Nation und Sprache auch dem sprachwissenschaftlichen Diskurs zugrunde gelegt wird, kommt jedoch besonders in der Verwendung der Begriffe «llengua pròpia» und «Normalisierung» zum Ausdruck.

\subsection{Der Begriff der «llengua pròpia»}

Bereits im Autonomiestatut Kataloniens, das 1979 in einer Volksabstimmung verabschiedet wurde, ist die katalanische Sprache als «llengua pròpia» von Katalonien bezeichnet (Art. 3.1). Auf diese offizielle Sanktionierung des spezifischen Status des Katalanischen gegenüber dem Kastilischen verweist auch Pujol in seiner Rede vom 22.03.1995:

«El català és la llengua pròpia de Catalunya». Ho diu l'Estatut, aprovat pel poble català i per les Corts espanyoles. El català, i només el català és la llengua pròpia de Catalunya» (Pujol 22.3.95, 178).

Die Bedeutung des Begriffes erklärt Pujol wie folgt:

«Què vol dir llengua pròpia? Segons el diccionari, propi és allò que és d'úna persona o d'una cosa en exclusió de tota altra, per tant és quelcom que contribueix a definir una persona o una cosa. Propi és el que és genuí en oposició al que és derivat. Propi és, continua dient el diccio-

genannte Thesen seinem Aufsatz als zentrale Aussagen zugrundelegt. «Es pot dir que llengua i nació caminen juntes», ist dann auch eine seiner Schlussfolgerungen. Er sieht dies auch darin bestätigt, dass der Nationalismus immer dann aufblühe, wenn die Sprache einen Fortschritt mache, und umgekehrt, die Erfolge der Sprache eine Verbreitung des Nationalismus hervorriefen: «Pel que fa al primer terç del segle present (entre 1900 i 1936), resulta que a cada moment fort del nacionalisme català correspon una conquesta en la relització de la llengua, i, a la inversa, els progressos de la normalització lingüística tenen llur repercussió en una expansió del nacionalisme» (Badia i Margarit 1988, 18). 
nari, quelcom que no és manllevat. O bé diu que és alló que designa un individu en oposició al que és comú» (Pujol 22.3.95, 178).

Synonym zu «propi» ist «genuí», Antonyme sind «derivat» oder «manllevat». Das Katalanische wird somit als Katalonien «ursprünglich» angestammte Sprache definiert. Dem gegenüber steht die Idee des «Von-Woanders-Stammen». Implizit schwingt in der Gegenüberstellung von «propi» und «derivat» die Differenz zwischen dem Katalanischen (als angestammte Sprache) und dem Kastilischen (als künstlich aufoktroyierte Sprache) mit.

In der Definition von «propi» als «allò que és d'úna persona o d'una cosa en exclusió de tota altra» steckt auch die Vorstellung, dass eine Sprache nur einer Nation eigen sein kann. Demnach wird vermittelt, alle Gebiete gleicher Sprache müssten eine Nation darstellen. ${ }^{14}$

Auf die Definition von «propi» folgt in Pujols Rede sodann folgender Abschnitt:

«Totes aquestes accepcions es poden aplicar al <català, llengua pròpia de Catalunya> i això no és d'extranyar perquè el català és la llengua històrica de Catalunya, és la llengua de Catalunya des dels orígins. I fou, en contra de que de vegades es dit sobretot fora de Catalunya, la llengua usual única fins fa cent anys. Es la llengua medul-lar, és la que li dóna personalitat pròpia i definida. Tot això només ho és el català» (Pujol 22.3.95, 178).

Die Tatsache, dass das Katalanische und nicht das Spanische die «llengua pròpia» von Katalonien sei, begründet Pujol durch dessen frühe Ansiedlung in Katalonien. ${ }^{15}$

Pujol führt als Synonym von «llengua pròpia» «llengua històrica» ein. In der katalanischen Linguistik ist dieser Begriff umstritten. Er wurde laut Branchadell eingeführt, um die Defizite der Begriffe «llengua originària» und «llengua territorial» auszumerzen. Diese wurden als Synonyme zu «llengua pròpia» verstanden, um auszudrücken, dass die Beziehung zwischen Sprache und Nation ursprünglich (originària) sei. Wie bei Pujol, der davon spricht, das Katalanische sei «llengua de Catalunya des dels orígins» (wobei im Dunkeln bleibt,

14 Diese Aussage ist freilich gefährlich, da sie entweder bedeutet, den anderen nicht Katalonien angehörenden Regionen, denen Katalanisch gesprochen wird (Balearen, Valencia, Andorra etc.) wäre das Katalanische nicht eigen, da es nur Katalonien eigen sei, oder aber, diese Sprachgebiete müssten in die katalanische Nation integriert werden bzw. sich in einer katalanischen Großnation vereinigen.

${ }^{15}$ Die Behauptung, das Katalanische sei vor hundert Jahren noch die einzige Sprache in Katalonien gewesen, ist historisch nicht zu belegen. Cf. hierzu Woolard, die meint, das Decreto de Nueva Planta (18.Jh.) sei lediglich «[...] the official sanction to the ongoing process» gewesen: «With the emigration to the Castilian court, the catalan aristocracy had begun to become castilianized in the late fifteenth century. By the seventeenth century, there is evidence that this language shift on the part of the dominant class had consequences for the general population, making familiarity with Castilian a possibility if not an everyday occurrence» (Woolard 1989, 21). 
ob er die Wurzeln Kataloniens oder die des Katalanischen meint), wurde die «llengua pròpia» damit als die Sprache definiert, die in Katalonien entstanden ist. So formuliert es Aina Moll bereits 1981:

«El catalán es la lengua propia de Cataluña, porque es la lengua que se forjó en Cataluña a lo largo de los siglos, por evolución natural del latín [...]» (Moll 1981, 14).

Problem dieser Sichtweise sei, so Branchadell, dass es sich als unmöglich erweise, jedem Territorium dieser Welt die ihm eigene Sprache aufgrund von Ursprünglichkeit zuzuordnen (Branchadell 1997, 144). Deshalb schlugen andere Normalisierer vor, den Begriff «llengua històrica» zu verwenden, so dass auch in anderen Gebieten entstandene Sprachen, die vor langer Zeit im betreffenden Territorium ansiedelten, als «pròpias» bezeichnet werden könnten. Hier dachte man vor allem an die Notwendigkeit, auch den Balearen und Valencia das Katalanische als eigen zuzuordnen, obwohl es hier erst später Fuß fasste. ${ }^{16}$ Daher schlug z. B. Isidor Marí, Professor für Sprachwissenschaft an der Universitat Oberta de Catalunya, 1992 in seiner Funktion als «Subdirector General de Política Lingüística» folgendes vor:

«Aquestes llengües, tot i ser en realitat extraterritorials, a causa d'altres factors demogràfics o polítics poden passar a ser dominants i arribar a ser considerades també històriques al mateix territori [...], amb un estatus igual o encara més alt que la llengua originària» (zitiert nach Branchadell 1997, 146s.). ${ }^{17}$

Diese Definition würde jedoch bedeuten, dass auch das Kastilische als «llengua pròpia» Kataloniens akzeptiert werden müsste. Der Begriff der «llengua pròpia» ist im Diskurs jedoch eben deshalb grundlegend, weil er dem Katalanischen Vorrang vor dem Kastilischen als nicht «pròpia» bescheinigen kann. ${ }^{18}$ Dieses Problem löst Pujol, der auch von «llengua històrica» spricht, durch die Verdrehung der historischen Tatsachen, also der Behauptung, das Katalanische sei «llengua usual única fins fa cent anys» (Pujol 22.3.95, 178) gewesen. Diese Sichtweise können die Wissenschaftler nicht guten Gewissens vertreten, so dass sie lieber bei der Definition von «llengua pròpia» als «llengua originària» bleiben (Branchadell 1997, 123s.). Dabei leitet sich diese Defini-

\footnotetext{
${ }^{16}$ Die Balearen und Valencia wurden erst im $13 \mathrm{Jh}$. von Katalonien erobert. Vorher waren die Territorien in den Händen der Araber.

17 Aus: Isidor, Marí, Algunes distincions objectives essencials per l'aplicació igualitària dels drets lingüistics, in: Drets lingüistics $i$ drets culturals a les regions d'Europa. Actes del Simposi Internacional (Girona, 23-25 d'abril de 1992). Barcelona, Generalitat de Catalunya, 46.

18 Wenn auch das Kastilische nun als «llengua pròpia» anerkannt würde, würde dies, wie Branchadell feststellt, den gesamten Rechtfertigungsdiskurs der Normalisierung obsolet machen: «Si el castellà arriba a ser percebut com una llengua pròpia de Catalunya, el (poc) discurs ideològic que justifica els esforços de normalització lingüística del català quedaria malmès seriosament» (Branchadell 1996, 29).
} 
tion nicht aus wissenschaftlich festgestellten Tatsachen ab, sondern orientiert sich an den Zielen der Sprachpolitik, nämlich dem Vorrang des Katalanischen. Der Begriff «llengua pròpia» beinhaltet in dieser Form die sprachnationalistische Annahme einer eindimensionalen und unveränderbaren Beziehung zwischen Sprache und Nation: Nur das Katalanische kann «llengua pròpia» sein, und zwar weil es seinen Ursprung in dem als Nation angesehenen Territorium hat (cf. auch das oben angeführte Zitat von Aina Moll).

Die Beschwörung der unveränderlichen Beziehung zwischen dem als Nation definierten Territorium und der Sprache ist im sprachpolitischen Diskurs deshalb grundlegend, weil eine Beziehung zwischen der Sprache und den Bewohnern dieses Territoriums mehrheitlich verloren gegangen ist und die Normalisierung sich als Korrektur dieser Entwicklung nur rechtfertigt, wenn der Verlust als «falsch» angesehen wird. Der Begriff «llengua pròpia» impliziert daher auch eine höhere Bewertung der Verbindung zwischen Territorium und Sprache als der zwischen Individuum und Sprache: nicht die der Bevölkerung eigene Sprache ist auch dem Territorium eigen, sondern umgekehrt, die dem Territorium «von Anfang an» eigene Sprache sollte auch den Individuen eigen sein, egal wie sich der Sprachgebrauch der Bevölkerung im Laufe der Geschichte verändert hat. So erklärt sich z. B. eine Feststellung von Miquel Reniu, Direktor der Direcció de Política Lingüística von 1988 bis 1996, der in einem Interview mit Avui (20.03.95) versicherte, dass, auch wenn das Kastilische die meistgesprochene Sprache in Katalonien sei, das Katalanische immer noch «llengua pròpia» bliebe (nach Branchadell 1997, 145s.).

\subsection{Der Begriff «Normalisierung»}

Auch hinter dem sprachwissenschaftlichen Begriff der «Normalisierung» ${ }^{19}$ kann sich die Ansicht der eindimensionalen und unveränderbaren Verknüpfung zwischen Sprache und Nation verbergen. Kann, denn dies hängt davon ab, welches als das Ziel der Normalisierung gilt, eine in den Sprachwissenschaften bisher nicht einheitlich gelöste Frage. ${ }^{20}$ Auch in Katalonien kursieren verschiedene Ansichten: Einige sehen den Erfolg der Normalisierung in dem

${ }^{19}$ Dieser von katalanischen Soziolinguisten entwickelte Begriff benennt «[...] den Übergang von einer von den Sprechern der dominierten Sprache (s. Diglossie) als anomal empfundenen oder beurteilten Sprachsituation zu einer normalen und impliziert ein sprachpolitisches Programm zur Emanzipation einer Minderheiten- oder Nationalitätensprache im Hinblick auf die Entfaltung aller ihrer Funktionen in der entsprechenden Sprachgemeinschaft» (Bochmann et al. 1993, 409).

${ }^{20}$ Zur Kritik am Begriff der Normalisierung cf. auch Kabatek, der meint, «dass [...] das Konzept «Normalisierung〉 [...] nie objektiv sein [kann], es bezieht sich stets auf eine Relation zu bestehenden Normen, etwa auf die gesellschaftliche Rolle des Kastilischen in Spanien oder die in anderen Gesellschaften üblichen Funktionen einer verbreiteten National- oder Standardsprache; dies wird deskriptiv als Norm festgestellt und dann zur Orientierungsgröße für das normativ gesetzte Ziel des Katalanischen» (Kabatek 1995, 28). 
Erreichen einer ausgeglichenen Situation von Zweisprachigkeit, andere in dem einer Diglossie zugunsten des Katalanischen und wieder andere in dem der katalanischen Einsprachigkeit.

Die Vertreter des Gleichgewichts zwischen beiden Sprachen, - dies ist übrigens auch das zur Zeit gesetzlich festgeschriebene Ziel der Normalisierungsmaßnahmen ${ }^{21}$ - finden sich vor allem in der Politik, da hier radikalere Ziele als politisch inkorrekt gelten und einen Verlust von Wählern bedeuten könnten. Dies gilt vor allem für Pujol, der als Repräsentant der Partei Convergència $i$ Unió einen gemäßigten Nationalismus vertritt. In seiner Rede vom 22.03.95 sagt er über das Ziel der Sprachpolitik:

«Bé, i dit tot això, què preten el Pla? Primera: no pretén cap regulació dels drets lingüístics individuals. Els drets individuals no es toquen. Això dóna garanties als catalanoparlants i als castellanoparlants. Pretén que ens anem acostant al bilingüisme igualitari, tal com abans l'he descrit. Aquell en el qual el procés faci que tothom conegui les dues llengües i que, si més no, en català pugui ser atés tothom» (Pujol 22. $03.95,196 \mathrm{~s}$.).

Weiter vorne in der Rede scheint dieser «bilinguisme igualitari» jedoch in gewisser Weise eingeschränkt, da das Katalanische als «centre de gravetat» desgleichen gelten soll. Pujol bezieht sich hier auf eine Entscheidung des spanischen Verfassungsgerichtes: ${ }^{22}$

\begin{abstract}
«Diu, doncs, repeteixo: <és constitucionalmente legítimo [das Sprachgesetz von 1983, K.S.] en cuanto responde a un propósito de integración y cohesión social en la Comunidad Autónoma cualquiera que sea la lengua habitual de cada ciudadano - $-\mathrm{i}$ continua, i ara els demano sobretot que s'hi fixin - <al igual que es legítimo que el catalán, en atención al objetivo de la normalización lingüística de Cataluña, sea el centro de gravedad de este modelo de bilingüismo> - i afegeix, i això també ès important $i$ ens hem de fixar - «siempre que ello no determine la exclusión del castellano como lengua docente de forma que quede garantizado su conocimiento y uso»» $(22.03 .95,179)$.
\end{abstract}

Pujol wiederholt gleich darauf insistierend den Satzteil «que el catalán, [...] sea el centro de gravedad de este modelo de bilingüismo» $(22.03 .95,179)$ und

${ }^{21}$ Im aktuell gültigen Sprachgesetz (Llei 1/1998) heißt es in der Präambel: «La modificació i l'actualització de la Llei del 1983 han de permetre també consolidar el compromis estatutari d'arribar a la plena igualtat pel que fa als drets i els deures lingüístics i, de manera especial, els de conèixer les dues llengües oficials i usar-les, cosa que comporta que, d'acord amb el marc estatutari vigent, els ciutadans i ciutadanes de Catalunya hauran de conèixer la llengua catalana i la castellana i tindran el dret d'usar-les».

${ }^{22}$ Es handelt sich um die Entscheidung über die Verfassungsmäßigkeit des ersten, 1983 verabschiedeten katalanischen Sprachgesetzes. Gegen dieses hatte bereits im Jahr seiner Verabschiedung der Rechtsanwalt Esteban Gómez Rovira geklagt, da er seine Kinder nicht gezwungen sehen wollte, Katalanisch zu lernen. Die Klage wurde durch verschiedene Instanzen gereicht, bis letztendlich am 23.12.1994 das Verfassungsgericht die Verfassungsmäßigkeit des Gesetzes bestätigte (El País, 24. 12. 1994). 
erweckt somit den Eindruck, für einen gewissen Vorrang des Katalanischen zu plädieren. Diesen Vorrang begründet er - auch dies mit Verweis auf die Entscheidung des Verfassungsgerichtes - als notwendig für eine Korrektur des Ungleichgewichtes zwischen beiden Sprachen zulasten des Katalanischen (Pujol 22.03.95, 187). ${ }^{23}$

Unter den meisten Normalisierungsbefürwortern, die mit der Wissenschaft verbunden sind, sind jedoch radikalere Stimmen zur Zielsetzung der Normalisierung zu finden. Der bekannte katalanische Soziolinguist Francesc Vallverdú befand bereits 1976, das Katalanische habe «primera llengua» in Katalonien zu sein (Vallverdú 1979, 133). Vor allem jedoch mit dem Fortschreiten der Normalisierung geht laut Branchadell eine Diskursverschärfung einher: Viele Sprachwissenschaftler schlossen aus dem Begriff, dass das Ziel der Normalisierung nicht nur ein reiner «Ausgleich» («reequilibri», «igualtat») sein solle, sondern durchaus «Hegemonie» und «Priorität» («hegemonia», «prioritat») des Katalanischen anzustreben seien (Branchadell 1997, 121). Überwiegend gebe man sich jedoch auch damit nicht zufrieden und fordere gar die vollständige Substitution des Kastilischen und somit die Erreichung des katalanischen Monolinguismus in Katalonien (Branchadell 1996, 22).

Dass diese Ansicht unter Wissenschaftlern besonders verbreitet ist, liegt sicherlich daran, dass die von den katalanischen Soziolinguisten Aracil, Ninyoles und Vallverdú entwickelte Theorie des Sprachkonfliktes erachtet, dass alle Zweisprachigkeit zum Sprachtod einer der Sprachen führe. Daher ist für sie die Einsprachigkeit in der Minderheitssprache die einzig mögliche Lösung des Sprachkonflikts, die nicht mit deren Sprachtod endet. Vallverdú beschreibt seine Vorstellung über den Normalisierungsprozess daher wie folgt:

\begin{abstract}
«[...] en el procés de normalització, es produirà un canvi qualitatiu en el conflicte lingüístic, quan el català assoleixi la plenitud d'ús, és a dir, la conquesta de tots els àmbits d'ús quan fan «normal〉 una llengua i la consegüent reculada en aquests àmbits d'ús del castellà, que a nivell públic encara té una forta implantació [...]. L'exigència de la plenitud d'ús per al català és compatible amb l'ús del castellà per part dels ciutatans que vulguin mantenir-lo com a primera llengua, a qui seran respectats els seus drets lingüístics, mentre no es produeixi un segon canvi qualitatiu que permetés d'aplicar més estrictament el principi de territorialitat» (Vallverdú 1992, 54).
\end{abstract}

Langfristig bedeutet demnach die Normalisierung eine Sprachenregelung nach einem «strikten» Territorialitätsprinzip, d.h. sie zielt auf die Erreichung einer möglichst hohen sprachlichen Homogenisierung des Territoriums, in der

23 Diese Idee ist unter dem Namen «positive Diskriminierung» auch unter Sprachund Rechtswissenschaftlern verbreitet. Die Bevorzugung des Katalanischen soll demnach nur eine begrenzte Zeitspanne betragen, bis der Ausgleich zwischen beiden Sprachen geschaffen ist. Fraglich bleibt jedoch, so auch Branchadell, wann bzw. ob überhaupt je der Abschluss dieser Phase beschlossen werden würde (Branchadell 1997, $26-32)$. 
auch die individuellen Sprachrechte der Kastilischsprecher nur so lange Platz haben, bis diese erreicht ist («mentre no es produeixi un segon canvi qualitatiu»).

Auch in Zitaten von Verantwortlichen, die in der Direcció de Política Lingüistica die Umsetzung des politischen Normalisierungsprogramms planen, ist die Forderung nach einem möglichst hohen Grad an Sprachhomogenität Standard. Aina Moll verkündete bereits 1985:

\begin{abstract}
«Normalitzar vol dir fer normal, oi? Quina seria la situació lingüística normal? En un territori on hi ha una llengua oficial que a més a més és la pròpia del país, el normal és que tots els ciutatans sàpiguen aquesta llengua i l'emprin en qualsevol situació [...]. Hem de tendir a que el català sigui veritablement la llengua pròpia d'aquí, que tota relació normal es faci en català» (zitiert nach Branchadell 1996, 25). ${ }^{24}$
\end{abstract}

Ihr Nachfolger Miquel Reniu beschrieb die zu erreichende Norm wenig später so: «aconseguir que el català torni a predominar en tots els àmbits de la nostra societat sense bandejar cap altra llengua» (zitiert nach Branchadell 1996, 105, meine Hervorhebung). ${ }^{25}$

Die von der Politik vertretene moderate Zielsetzung der Normalisierung, der «bilinguisme igualitari», wird also in der Wissenschaft gar nicht als erstrebenswert erachtet.

Wird als Ziel der «Normalisierung» der Monolinguismus in der Minderheitssprache oder zumindest ihr Vorrang angestrebt, so impliziert auch dies die sprachnationalistische Auffassung, jeder Nation könne nur eine Sprache (vorrangig) zugeordnet werden. Die hier innewohnende Vorstellung, die Sprachsituation müsse «wieder» in die «normale» Ausgangsposition zurück gebracht werden, impliziert zudem das Ideal der Unveränderbarkeit der Beziehung zwischen einer Sprache und «ihrem» Territorium («ihrer» Nation). Dynamiken der territorialen Sprachverbreitung, wie sie in Katalonien durch historische Umstände stattgefunden haben, gelten als illegitim und müssen rückgängig gemacht werden.

\title{
5.5 Sprachidentität als Nationalidentität
}

In den Ausführungen zum Sprachnationalismus hatte ich festgestellt, dass die Vorstellung des einsprachigen Individuums, also die Idee der eindimensionalen unveränderbaren Beziehung der Identität zu nur einer Sprache, sich aus der Definition von Sprachidentität als Nationalidentität bzw. daraus ergibt, dass die Sprachidentität sich eben aus der Sprache formt, die auch der Nation,

${ }^{24}$ Aus einem Interview mit El Món, nachgedruckt in Joan, Tudela, El futur del català. Una radiografía lingüistica, Barcelona, Publicacions El Món, 1986, 19-27, hier: 25.

${ }^{25}$ Aus: Miquel, Reniu, Un nou impuls a la política lingüística. Conferència pronunciada al Col-legi de Periodistes de Catalunya el dia 9 de juliol de 1990, Barcelona. 
dem das Individuum angehört, eigen ist. Ich will dies nun auch am katalanischen Diskurs zeigen.

In Pujols Rede vom 22.03.05 wird von vorne herein nicht unterschieden zwischen «Identität», verstanden als Identität eines einzelnen Menschen, und der Identität Kataloniens. Hierzu noch einmal die ersten beiden Sätze der Rede:

«[...] la llengua catalana, és un element bàsic de la nostra identitat, del nostre ésser com a poble. He dit algun cop, emprant la fórmula d'un filòleg basc, que el català és el nervi de nostra nació» (Pujol 22. 03. 05, $174)$.

Hier wird «nostra identitat» zunächst mit «nostre ésser com a poble» attributiert und im nächsten Satz ist im gleichen Sinne von «nostra nació» die Rede, so dass eine Unterscheidung zwischen Identität, Volk und Nation kaum mehr gegeben ist. Die Beziehung zwischen allen dreien konstituiert sich über Sprache («llengua catalana»), denn diese ist «element bàsic» aller.

Da er so illustrativ ist, sei auch noch ein Satz aus einer Rede von 1985 zitiert:

«[...] la llengua és [...] el nervi d'una col-lectivitat, és a dir, allò que fa que sigui el que és i allò que fa que se sigui el que un és [...]» (Pujol 30.6.85).

Die Sprache ist also Kern der Kollektivität und der Identität jedes Einzelnen. Die Sprache, die die Nation definiert, definiert gleichzeitig die Identität der Individuen.

Dass die über Sprache geformte Identität die Nationalidentität sein soll, wird auch bei den Sprachwissenschaftlern deutlich: Zunächst ist festzustellen, dass hier Sprachidentität oft mit Kulturidentität gleich gesetzt wird. Branchadell z. B. räumt dies selbst ein: «En aquest capítol hem barrejat conscientment les nocions d'identitat cultural i identitat lingüística» (Branchadell 1997, 212). Er geht an dieser Stelle auf das Gegenargument zur Normalisierung ein, das meint, man könne auch «auf Kastilisch» Katalane sein, ein Argument, das viele Kastilischsprecher in ihrem Protest gegen die Normalisierung formuliert haben. ${ }^{26}$ Branchadell argumentiert:

«Un cop més, la rèplica a aquetsa objecció hauria de tenir un caràcter empíric. Aquí no entrarem a discutir qüéstions de l'estil de si realment és possible ser català (o gallec) en castellà; tot el que hauríem d'establir és si els individus catalanoparlants se sentirien culturalment segurs si no hi hagués mesures especials de protecció per la seva llengua. El nostre parer és que la resposta seria negativa» (Branchadell 1997, 213).

Ein Katalanischsprachiger kann sich also niemals «kulturell sicher» fühlen, wenn seine Sprache in Gefahr ist. D.h. hier wird noch einmal bekräftigt, dass

26 So z. B. das Manifiesto de los 2300 von 1981: «[...] que se pueda ser catalán, vivir enraizado y amar a Cataluña hablando tanto en catalán como en castellano». 
die «kulturelle» Identität unweigerlich an die Sprache gebunden ist. Die Äußerung impliziert zudem eine eindimensionale Verbindung zwischen Sprache und dieser Identität: die «kulturelle Sicherung» ist nur durch eine Sprache, das Katalanische, möglich.

Das Wort «national» wird bei Branchadell vermieden, da er sich in seinem Buch bemüht, den Normalisierungsdiskurs auf «liberale» Füße zu stellen (daher der Titel des Buches Liberalisme $i$ normalització lingüistica). Ich gebe aber zu bedenken, dass die kulturelle Identität hier dennoch die katalanische Identität meint, die ebenso als nationale Identität gefasst werden kann. Dies wird jedoch nur bei den «radikaleren» Vertretern deutlicher. Ich wiederhole das Zitat von Arenas Sampera zur Sprache als «nervi de la nació»:

«La llengua, així de clar, és una, la pròpia del país; les altres s'han de conéixer i dominar però no poden suplantar el factor idiomàtic que és el nervi de la nació i que infon una determinada manera de ser $i$ actuar [...]» (Arenas 1991, 78, meine Hervorhebung).

Hier prägt die Sprache, die die Nation definiert, gleichzeitig die «Art zu sein». Diese von der Sprache geprägte «Art zu sein» muss somit eine nationale Identität sein.

Dass das «Katalanisch sein», die nationale Identität, nur über die Annahme der katalanischen Sprache erreicht werden kann, macht auch Aina Moll 1981 in einem in El País veröffentlichten Artikel mit dem Titel «La normalización del catalán» deutlich. Als eines der Grundprinzipien der Normalisierung nennt sie:

«No es posible ser catalán y rechazar la lengua de Cataluña. Todo catalán, independientemente de su origen étnico y lingüístico, debe aceptar el catalán como lengua propia del país y común a todos sus habitantes» (Moll 1981, 6, Hervorhebung von der Autorin).

«Katalane sein» ist hier gemäß der Definition des moderaten katalanischen Nationalismus nicht ethnisch definiert. Die Aussage enthält jedoch einen Widerspruch, wenn es zunächst heißt, man könne kein Katalane sein, wenn man das Katalanische ablehne, dann jedoch von Katalanen auch als denjenigen spricht, die eine andere «sprachliche Herkunft» haben. Das soll Kataloniens viel gepriesene Offenheit, alle Bewohner Kataloniens als Katalanen zu akzeptieren, andeuten, knüpft diese Akzeptanz jedoch gleichzeitig an eine grundlegende Bedingung: die «echte» katalanische (National)Identität kann nur durch eine Identifizierung mit der katalanischen Sprache erlangt werden. Der Wunsch sprachlicher Assimilierung und Homogenisierung kann nicht deutlicher ausgedrückt werden. Die Sprachidentität aller Bewohner Kataloniens soll mit ihrer Nationalidentität gleich geschaltet werden. Sprache («catalán»), katalanische Identität («ser catalán») und Territorium («lengua propia del país y común a todos sus habitantes») werden einmal mehr als untrennbar miteinander verbunden dargestellt. 
Dass Sprachidentität mit Nationalidentität zu verbinden sein Ziel ist, soll im Folgenden zusätzlich an einem dem Diskurs innewohnenden Widerspruch erläutert werden: nämlich dem, dass auf der einen Seite die Bewahrung der Sprachidentität der Katalanen Normalisierungsprogramme rechtfertigt, auf der anderen Seite jedoch immer wieder kritisiert wird, den Katalanen mangele es an Willen, ihre Sprache zu retten:

Bereits im Abschlussdokument des II. Intermationalen Kongress für Katalanische Sprache (1986) heißt es, die Verzögerung der Normalisierung habe ihren Ursprung in der Unentschlossenheit von Institutionen und Bevölkerung, die Idee der «llengua pròpia» anzunehmen und ihre Sprachrechte auszuüben (Bochmann et al. 1993, 415s.). 1990 bestätigt auch der Politologe Joan Colomines, damals Präsident der Comissió de Política Cultural del Parlament de Catalunya in seinem Informe sobre la llengua, dass das Ziel der Normalisierungsprogramme erst einmal überhaupt die Überzeugung der Bevölkerung von ihrer Notwendigkeit sein müsse:

«La veritat és que no hem aconseguit interessar la gent en el nostre procés de normalització de la llengua catalana, i ho dic així perquè aquest és l'objectiu real» (zitiert nach Branchadell 1996, 204). ${ }^{27}$

Und auch der weiter oben bereits zitierte Direktor des Servei d'Ensenyament del Català (SEDEC) Joaquín Arenas i Sampera konstatiert:

«Però acabem de parlar, rattles amunt, de la conscienciació lingüística de la nostra societat, i referent a aquest punt, hem de reconéixer que, per dissort, és molt pregona quan no inexistent» (Arenas 1991, 22).

Und an anderer Stelle:

«Val pena de remarcar que els prejudicis que puguin existir en pro de la normalització de la llengua catalana com a idioma del país són fruit d'una desinformació absoluta que existeix entre la població pel que fa a la importància del fet lingüístic, del què vol dir llengua i poble i de la interrelació entre llengua i pensament» (Arenas 1991, 61).

Die Katalanen müssen also über den symbolischen Wert ihrer Sprache erst noch aufgeklärt werden. Dies wird als Ziel der Sprachpolitik erachtet. Wie kann jedoch andererseits behauptet werden, dass die Sprachidentität einer Bevölkerung verteidigt werden soll, die deren Wert (noch) gar nicht kennt und für die sie sich nicht interessiert?

Dies erklärt sich nur daraus, dass der Normalisierungsprozess sich eben nicht unbedingt an der Frage orientiert, welche Sprache die Bevölkerung bevorzugt spricht, sondern daran, welche die dem Territorium zugeordnete Sprache ist, die somit auch die Bevölkerung zu übernehmen hat, die dort wohnt. Es geht also nicht um die Verteidigung der Sprachidentität aller Individuen, sondern um die Verteidigung der Sprachidentität derjenigen, die eben diese nationale Sprache sprechen, bzw. darum, denen, die dies noch nicht tun, die

${ }^{27}$ Zuerst in: Revista de Catalunya 44 (1990), 48-56. 
Sprachassimilierung nahe zu legen. Nur so erklärt sich, dass in Texten eines «hardliners» wie Arenas Sampera «Muttersprache» letztendlich mit «Sprache des Territoriums» gleichgesetzt wird:

\begin{abstract}
«Hi ha, doncs, una dicotomia entre llengua materna i llengua adquirida i una contradicció entre els conceptes llengua materna i llengua de la mare. De tal manera que es pot afirmar que tant a la Conferència de Bilingüisme del 1929 com a la UNESCO des del 1951 fins a l'actualitat, quan s'esmenta el concepte llengua materna es fa en el sentit de llengua materna de la terra, és a dir, de llengua territorial. Per això el Programa d'Immersió no contradiu en cap aplicació els postulats de l'organització internacional, ans al contrari, l'aplica plenament per la coincidència definitòria entre llengua pròpia i llengua materna. Ser educat i instruït en la llengua mare de la terra és un dret del infants» (Arenas 1986, 17, Hervorhebung vom Autor). ${ }^{28}$
\end{abstract}

Die Verwendung von «Territorium» verschleiert hier nur, dass sich dahinter die Idee des nationalen Territoriums, also der Nation befindet, so dass, ähnlich wie in dem Zitat von Weisgerber, das Individuum über die Sprache an die Nation gebunden wird.

Die Unauflösbarkeit dieser Bindung wird beschworen, wenn der gleiche Autor an anderer Stelle auf den ebenfalls in der katalanischen Soziolinguistik akzeptierten Begriff des «Selbsthasses» («autoodi») verweist. ${ }^{29}$ Dieser beinhaltet die Idee, dass das Identitätsbewusstsein der Katalanen zwar an sich vorhanden ist, jedoch durch die jahrhundertlange Negierung der katalanischen Kollektividentität, die das Katalanischsein als etwas Negatives hat erscheinen lassen, verdrängt wurde, was zu einem Minderwertigkeitskomplex führte, der heute dazu beiträgt, dass die Katalanen gegen einen als «verschüttet» geltenden und ihnen dennoch als «eigenen» unterstellten Willen, sich als Gemeinschaft $\mathrm{zu}$ verstehen, handeln:

«L'autoodi i la distorsió són els factors que han portat molts catalans autòctons a actuar contra la pròpia identitat» (Arenas 1991, 63).

Zweck der Ausführungen Ninyoles' ist es, eine Theorie zur Gruppenidentität auf die Sprachidentität anzuwenden. Die Annahme einer neuen Gruppen- oder Kultur- und damit Sprachidentität kann laut Ninyoles zwar glücken, jedoch bringe die Leugnung der eigenen (Sprecher-)Gruppe meist einen Identitätskonflikt mit sich:

\footnotetext{
${ }^{28}$ Arenas möchte so rechtfertigen, dass das UNESCO-Grundrecht auf Unterricht in der Muttersprache nicht verletzt werde, wenn kastilischsprachige Kinder auf katalanisch unterrichtet werden. Der sprachpolitische Diskurs Kataloniens geriet hier mit sich selbst in Widerspruch, da er zu Anfang der Bewegung dieses Recht für katalanischsprachige Kinder einforderte, es kastilischsprachigen Kindern jedoch zunehmend nicht mehr zugestehen wollte. Was Arenas hier schon 1986 forderte, wurde 1992 (Artikel 3.1 des Dekretes 75/92 vom 9.3.92) umgesetzt: Seither ist das Katalanische einzige Unterrichtssprache öffentlicher Schulen in Katalonien.

${ }^{29}$ Rafael Ninyoles entnahm den Begriff der Sozialpsychologie Kurt Lewins (Ninyoles 1995, 76). Zur Geschichte des Begriffes cf. Kabatek 1994.
} 


\begin{abstract}
«Diem que l'autoodi és el sentiment d'inferioritat que experimenten determinats individus per posseir els trets que els identifiquen com a membres d'un grup. L'actitud més simple és, naturalment, la de negar la pertinança a aquest grup. Quan una comunitat lingüística és objecte de discriminació, els seus membres poden generalment adoptar l'idioma dominant i abandonar el propi [...]. L'individu que s'enforça a negar els seus vincles amb el propi grup, normalment parteix un greu conflicte. El canvi d'identitat cultural no es produeix sense resistències internes» (Ninyoles 1995, 80).
\end{abstract}

Die Kultur- und somit auch die Sprachidentität gelten als unveränderbar. Das Schicksal des Individuums ist an seine Sprachidentität gekettet. Es kann sich nicht aus ihr befreien und leidet unter Konflikten, sobald es die Sprache (und damit Kultur/Gruppe) wechselt. Es findet sich hier also der Gedanke der Schicksalsverknüpfung von Sprache und Individuum wieder.

\title{
5.6 Kollektive Sprachrechte
}

Dass man häufig von Sprachidentität spricht und Nationalidentität meint, zeigt auch die Hinwendung des Diskurses zu dem Begriff der «kollektiven Sprachrechte». Die Bewahrung kollektiver Sprachrechte bedeutet automatisch die Einschränkung der individuellen Sprachrechte, da argumentiert wird, dass zum Erhalt der Sprache des Kollektivs die Individuen, die diese nicht sprechen, sich diesem zu beugen haben. Das «Kollektiv», das hier gemeint ist, ist diejenige Sprachgemeinschaft, die die Sprache spricht, die als die dem Territorium/der Nation eindimensional und unveränderbar zugeordnete gilt. Dies führt Pujol in seiner Rede vom 22.03.95 aus:

«En el camp lingüístic el predomini del dret col-lectiu sol conduir a l'anomenat model territorial. Lúnica llengua admesa oficialment és la del territori: el flamenc a Flandes, l'alemany al cantó de Zurich o el francès a Ginebra. En el model del dret individual, en canvi, no hi ha una sola llengua oficial en el territori i tothom pot emprar, i ha de poder emprar, la que prefereixi. En teoria hi ha llibertat lingüística total» $(\mathrm{Pu}-$ jol 22.03.95, 188).

Pujol warnt vor der Anwendung dieses territorialen Prinzips:

«Si a Catalunya s'hagués instaurat una situació de predomini del dret col-lectiu, si s'hagués aplicat el model territorial, caldria parlar especialment dels perills que això comporta, que en comporta. Però el sistema que hi ha a Catalunya s'inclina pels drets individuals» (22.03.95, 188).

Dies ist verwunderlich, denn bereits zwei Wochen vor der Rede hatte die Generalitat einen Pla General de Normalització Lingüistica verabschiedet, der zwar eine Berücksichtigung der individuellen Sprachrechte vorsieht, aber nur solange diese nicht «el dret col-lectiu de la comunitat lingüística catalana a la llengua pròpia del territori» beeinträchtigen (zitiert nach Branchadell 
1997, 129). ${ }^{30}$ Pujol verschleiert dies in seiner Rede noch. Erst bei genauerem Hinsehen ist auch hier ein Votum für die Territorialisierung zu entdecken, spricht er doch nicht von strikter Einhaltung der individuellen Rechte, sondern von «Tendenz» dazu («s'inclina pels drets individuals») und verlangt bereits im nächsten Satz eine «territorialització en certs àmbits» (Verwaltung, Justizwesen und Polizei) (Pujol 22.03.95, 188s.).

Dass die kollektiven Sprachrechte zunehmend eingefordert werden, begründet sich daraus, dass (statt ausgeglichenem Bilinguismus) zunehmend der Vorrang des Katalanischen, wenn nicht die katalanische Einsprachigkeit angestrebt wird. Beide Ziele können nur erreicht werden, wenn (Noch)Kastilischsprecher zum Katalanischen wechseln. Dazu müssen, können sie vom Diskurs selbst nicht überzeugt werden, ihre individuellen Sprachrechte eingeschränkt werden. Während also die Normalisierungsbewegung in ihren Anfängen für die Einhaltung der individuellen Rechte der Katalanischsprecher eintrat, verschiebt sich die Argumentation heute zum Recht des Kollektivs mit der Konsequenz, dass den Kastilischsprechern eben diese individuellen Rechte, für die man früher eintrat, nicht mehr zugebilligt werden. ${ }^{31}$

Aus dem Paradox, dass Rechte für die eigene Gruppe eingefordert werden, der anderen jedoch nicht zugestanden werden sollen, kann jedoch das Umschwenken auf die kollektiven Rechte letztendlich auch nicht heraushelfen, birgt dies doch im Endeffekt den gleichen Widerspruch: auch hier werden die Sprachrechte nur für einen bestimmtes Kollektiv eingefordert. Als Kollektiv könnten ja letztendlich auch die Kastilischsprecher und auch ausländische Zuwanderer gelten. Beide haben in Katalonien ebenso kein Recht, ihre Sprache in der Schule zu erlernen, wie in anderen Staatsnationen. Welchem Kollektiv die kollektiven Sprachrechte zugesprochen werden, hängt also letztendlich ebenso wie bei den individuellen Sprachrechten davon ab, ob die diesem Kollektiv zugeordnete Sprache diejenige ist, die dem nationalen Territorium als (unveränderbar und eindimensional) «eigene» zugeordnet wird.

Hieran wird noch einmal deutlich, dass von schützenswerter Sprachidentität immer nur dann die Rede ist, wenn diese mit der Nationalidentität zusammen fällt. Eine außernationale Sprachidentität hingegen erscheint nicht als schützenswert.

30 Aus: Pla general de normalització lingüística. Aprovat pel Govern de la Generalitat de Catalunya el dia 7 de març de 1995, Barcelona, objectiu 2.

31 Die Kastilischsprecher sehen ihre Sprachrechte zunehmend als verletzt an. In den 90er Jahren haben sich daher unzählige Organisationen begründet, die dies anprangern, z. B.: Asociación por la Tolerancia y contra la Discriminación (1992), Coordinadora de Afectados en Defensa de la Lengua Castellana (CADECA) (1993), Asociación por la lengua española en la Administración de Justicia (1994), Asociación de Profesores por el Bilingüismo (APB) (1994), Convivència Cívica Catalana (1997). 


\section{Schlussfolgerungen}

Sprachnationalismus wurde im vorliegenden Aufsatz definiert als ein Diskurs, der die Begriffe «Sprache», «Nation» und «Identität» vergegenständlicht und in dieser Form miteinander in Beziehung setzt, wobei diese als eindimensional und unveränderbar aufgefasst wird, so dass das Schicksal von «Identität» und «Nation» untrennbar mit dem der Sprache verknüpft erscheint. «Identität» wird als «nationale Identität» verstanden, und durch deren unauflösbare, statische Beziehung zur Sprache verschmelzen die Begriffe von Sprachidentität und Nationalidentität.

Die Analyse erbrachte, dass der sprachpolitische Diskurs in Katalonien dieser Definition des Sprachnationalismus entspricht. Sprache wird hypostasiert, als naturgegebene Entität angesehen, die dem Menschen gegenübersteht und in der Lage ist, der Nation eine «Stütze» zu sein. Sie ist das konstituierende Element von Nationen. Nationen werden damit als homogene Sprachgemeinschaften definiert. Jeder Nationen wird daher nur eine Sprache als eigene, originäre Sprache zugeordnet. Später in der Nation angesiedelte Sprachen werden als «fremde», «nicht genuine» und daher weniger rechtmäßige Sprachen angesehen. Diese Denkweise spiegelt sich vor allem in der Verwendung der Begriffe «llengua pròpia» (als einzig rechtmäßige Sprache der Nation ausgewiesen durch ihre Ursprünglichkeit) und «Normalisierung» (als Sprachpolitik, die die Wiederherstellung einer «ursprünglichen», verloren gegangenen Beziehung zwischen Sprache und Nation zum Ziel hat). Das Schicksal der Nation wird als mit dem der Sprache verwoben dargestellt. Die Bedrohung der jeweiligen Sprache bedingt die Bedrohung der Nation.

Auch Individuen wird nur eine Sprache als eigene, originäre Sprache zugeordnet. Die Beziehung des Einzelnen zu dieser Sprache ist nicht auflösbar, da das Individuum im Falle eines Sprachverlustes an einem internen Konflikt («Selbsthass») leidet. Diese Schicksalsverknüpfung zwischen Sprache und Individuum dient der Bindung des Individuums an die Nation, denn als schützenswerte Sprachidentität gilt nur diejenige, die aus der Nationalsprache entspringt. Dies erklärt auch die Hinwendung des Diskurses zur Einforderung kollektiver Sprachrechte, die nur für dasjenige Kollektiv gilt, das über die dem Nationalterritorium als «eigen» zugeordnete Sprache an die Nation geknüpft werden soll.

Die Gegenüberstellung des politischen Diskurses von Jordi Pujol und des wissenschaftlichen (von in der Normalisierung engagierten Soziolinguisten) hat ergeben, dass in beiden die gleichen Argumente und Begriffe auftreten, so dass der Diskurs wissenschaftlichen Ursprungs den politischen unkritisch rezipiert und weiter trägt. Der Zusammenfall von Sprache und Nation wird in Form der Definition der «llengua pròpia» als «llengua originària» und der Definition der Normalisierung als Streben nach Monolinguismus unter Wissenschaftlern teilweise gar noch expliziter eingefordert als bei Pujol. 


\section{Abschließende Bemerkungen: Minderheitssprachenförderung und Nationalismus}

Die Parallelisierung von Sprache, Nation und Identität, die dem sprachpolitischen Diskurs Kataloniens innewohnt, dient einem bestimmten Zweck: sie soll die Sprache zum essentiellen Beweismittel der Differenzierung zwischen «authentischen» Nationen (und Nationalidentitäten) machen. Eine Sprachpolitik, die so argumentiert, ist nationalistische Politik. Ihr Ziel besteht in der Verbreitung eines Diskurses, der der Bevölkerung den symbolischen Wert von Sprache als Nationalsprache und mit diesem Sprach- auch Nationalbewusstsein vermitteln möchte. ${ }^{32}$

Nicht nur die nationalistischen Forderungen der Katalanen, auch die der Basken, der Galicier, der Flamen und Korsen sind sprachpolitisch begleitet, genauso wie es die geglückten Unabhängigkeitsbestrebungen der Slowakei und der verschiedenen Länder in der ehemaligen Sowjetunion waren.

Der sprachpolitische Diskurs ist Teil eines umfassenderen Diskurses, dem der Verteidigung nationaler Minderheiten. Seinen Ursprung hat dieser in den linken Anti-Imperialismustheorien der 60er Jahre, die u. a. die Negierung ethnischer Identitäten in Drittweltländern durch die Nationalstaaten anprangern. Der Historiker und Vertreter der okzitanischen Minderheitsbewegung Robert Lafont und der amerikanische Soziologe Michael Hetcher wendeten erstmals diese Unterdrückungstheorien über den Begriff des «internen Kolonialismus» auch auf die regionalistischen Bewegungen in Europa an (SchulzeMermeling 1994, 43s.). In dieser Form wurde der Diskurs populär. Sein prägendes Charaktermerkmal ist, dass er den Minderheitsnationalismus als emanzipatorischen progressiven Gegenpol zu rechtem konservativen imperialistischen Staatsnationalismus definiert. Dadurch, dass er daher zwar eine bestimmte Form des Nationalismus kritisiert, eine andere jedoch verteidigt, beinhaltet er letztendlich die gleichen Grundprämissen des nationalistischen Diskurses wie sein scheinbarer Gegendiskurs: Während seine Nationalismuskritik sich darauf beschränkt, die Staaten der Erfindung einer «nicht legitimen» Nation zu beschuldigen, gelten die sogenannten Minderheitsnationen jedoch als legitime «wahre» Nationen. Kritisiert wird also nicht der Nationalismus und somit der Begriff der Nation an sich, sondern nur das Herstellen

\footnotetext{
${ }^{32}$ Pujol selbst definiert in einer Rede von 1988 Sprachpolitik als Teil dessen, was er «política de nacionalització de Catalunya» nennt, also der Identitäts- und Bewusstseinsschaffung in der katalanischen Bevölkerung: «[...] vaig parlar del que vaig anomenar 〈política de nacionalització> de Cataluña, que afecta els nostres signes d'identitat, els nostres símbols, la nostra consciència col-lectiva. Iniciatives com [...] el reforçament de la política de nacionalització de Cataluña, amb especial accent eb l'ús social del català [...] i com aquestes, moltes més iniciatives. [...] Limportant és que volem reforçar el sentiment i la consciència nacionals de Catalunya i tots els seus signes d'identitat. [...] Per tant, que ningú no s'inquieti [...] si aconseguim, com ens proposem fer, que Catalunya sigui en tot més forta, també en la seva consciència nacional» (5. 10.88, 84).
} 
von «falschen» Nationen innerhalb eines als unrechtmäßig angesehenen Nationalismus. Vorausgesetzt wird hingegen die Existenz eines rechtmäßig vertretenen «guten» Nationalismus, der auf der Unterteilung der Welt in «authentische» Ethnien beruht. ${ }^{33}$ Dass diese «authentischen» ethnisch unterschiedenen Nationen ebenso Konstrukte sind und ihre Forderungen nach Eigenständigkeit auf den gleichen Prinzipien wie denen des romantischen Nationalismus fußen, nämlich, dass die Nationen idealerweise kulturell und sprachlich homogen sein und ihre Selbstbestimmung in einer politischen Einheit, am besten einem eigenem Staat, verwirklichen sollen, wird nicht kritisch betrachtet.

Auch in der katalanischen Normalisierungsbewegung wurde der Unterschied zwischen dem «guten», «zivilen», «kulturellen» und dem «schlechten», «imperialistischen» «staatlichen» Nationalismus von Anfang an hervorgehoben. So ist bereits in dem berühmten 1979 von Universitätsprofessoren lancierten Manifest für den Erhalt des Katalanischen Una nació sense estat, un poble sense llengua zu lesen:

«Hi ha nacionalismes, com ara l'espanyol o el francès, sorgits de la necessitat de justificar i de donar cohesió interna a superstructures estatals artificioses, conformades tot al llarg del procés annexionista emprès per un estat imperialista; nacionalismes, doncs, de base espiritualista que han hagut de recórrer a la metafísica més demagògica [...] per tal de presentar com un tot el que no eren més que nacions diverses sotmeses a l'arbitri i interès de la classe dominant d'una sola d'elles. El catalanisme, en canvi, va ser des del primer moment un nacionalisme de base naturalista, és a dir, fonamentat en realitats objectives, i això no perquè no tenia cap estat a justificar (el tenia, en tot cas, a conquerir), sinó perquè les exigències amb què formulava els seus objectius i els seus drets es basaven en la incontrovertible constatació dels trets diferencials de la societat catalana, una societat conformada unitàriament de manera natural per una mateixa història secular compartida, una mateixa llengua i una mateixa cultura. Era, doncs, un nacionalisme ètnic (que cal no confondre amb el racial), la millor fonamentació teòrica i pràctica del qual, a l'hora de lluitar per Catalunya i les seves llibertats nacionals, era precisament la de mostrar les més que evidents diferències històriques, lingüístiques, socials, culturals, econòmiques, etc., que aquesta ètnia presentava en relació amb la dels espanyols» (Argente et al. 1979, meine Hervorhebungen).

Die Argumentation im Manifest führt sich jedoch selbst ad absurdum, wenn sodann behauptet wird, die «ethnische» Homogenität dieser «natürlichen» Nation sei durch die «Zuwanderung» (hiermit ist der Zuzug von Spaniern aus

33 Anderson sieht diesen Fehlschluss der Nationalismuskritik voraus, wenn er bemerkt, dass bereits einer der großen Theoretiker des Nationalismus, Ernest Gellner, in seiner Kritik der Nation das «Erfinden» nicht, wie Anderson selbst, als «Vorstellen» begreift, sondern vielmehr als «Herstellung von Falschem». Während Anderson alle Nationen von vorne herein als erfunden ansieht, impliziert Gellner, es gäbe im Gegensatz zu den konstruierten Staaten «wahre» Gemeinschaften (Anderson 1993, 16). 
anderen Regionen gemeint!) verloren gegangen (und daraus resultierten dann auch die Probleme der Sprache):

\begin{abstract}
«Ara bé, a conseqüència de les grans immigracions dels darrers decennis, la composició ètnica del Principat s'ha vist radicalment alterada, fins al punt que avui la seva societat no resulta ni de molt homogènia, sinó tot al contrari, car es troba escindida en dos grans grups més que diferents entre si. Aquesta nova situació no tan sols ha originat i origina una llarga sèrie de problemes pràctics relatius a la mútua convivència d'uns i altres, sinó que també fa trontollar les bases ara addü̈des d'homogeneïtat ètnica en què de sempre s'havia fonamentat el catalanisme històric. La incertesa resultant, teòrica i ideològica, es tradueix essencialment en una crisi del concepte d'identitat catalana i en nous motius de recel i incomoditat davant la llengua autòctona» (Argente et al. 1979, meine Hervorhebung).
\end{abstract}

Hier entlarvt der angeblich gute Nationalismus sich also selbst als ausgrenzend und als auf dem Ideal der inneren Homogenität der eigenen Nation beruhend, die diese jedoch ebenso wenig besitzt wie jeder etablierte Nationalstaat. Es zeigt sich, wie absurd die Unterscheidung zwischen verschiedenen Nationalismen ist, denn jeder Nationalismus basiert auf dem gleichen Minimum an Prämissen: der inneren Homogenität und der äußeren Abgrenzung. Beide existieren jedoch immer nur als Idee, die diskursiv oder zur Not auch gewaltsam zur Realität gemacht werden soll.

Das Manifest Una nació sense estat, un poble sense llengua, das heute noch als Meilenstein der Normalisierungsforderungen gilt und auch in der katalanischen Linguistik rezipiert wurde, ist ein typisches Beispiel dafür, dass die Rettung der katalanischen Sprache mit der Rettung der katalanischen Nation verknüpft wird. Antoni Badia i Margarit kommt in seiner oben bereits zitierten Rede auf der Konferenz der Academia de la Llingua Asturiana so auch folgerichtig zu dem Schluss, dass man aus dem Manifest nur folgern könne, dass eine Normalisierung des Katalanischen die Unabhängigkeit Kataloniens voraussetze:

«No menys lenta i laboriosa és la normalització. Com es desprén de la
mateixa paraula, normalitzar una llengua significa <er-la normal>, és a
dir, fer que els seus parlants vencin la diglòsia, la inercia, la por, la
mandra. [...] Que el català es normalitzi, ¿voldrà dir que això requereix
la independència política? Teòricament sí (si ens atenem als arguments
que s'hi esgrimeixen [im Manifest, K.S.]. Si el català no aconseguieux
unes estructures suficients de poder, ¿voldrà dir això que va de dret a
la substitució, és a dir, a la desaparició? Teòricament, sí (pels mateixos
raonaments que en el primer supòsit)» (Badia i Margarit 1988, 19).

Der Fall des Katalanischen ist nicht der einzige: generell ist der Diskurs der Rettung von Minderheitssprachen nicht ohne Grund zeitgleich mit dem Aufbegehren der Minderheitsnationen populär geworden. Und dass es sich hierbei keinesfalls um einen marginalisierten Rand- und Gegendiskurs handelt, zeigt ein regelrechter «Boom» des politischen und sprachwissenschaftlichen Interesses an Minderheitssprachen. Dies ist erkennbar an Beschlüssen wie der 
«Europäischen Charta der Regional- und Minderheitensprachen» (1992), der «Universellen Deklaration der Sprachenrechte» (1996), an EU-Projekten zur Untersuchung der Situation von Minderheitssprachen wie der «EuromosaicStudie», der Einrichtung von Finanzierungsfonds und Hilfsprogrammen für Minderheitssprachen (Sprachunterricht, Unterrichtsmaterial, Normalisierung, Umfragen, Filme, Videos, Übersetzungen) und der Durchführung von Konferenzen und Kongressen wie dem «Europäischen Kongress der Sprachplanung» (1995) und der «Weltkonferenz der Sprachenrechte» (1996).

Zwar setzt sich die Minderheitssprachenbewegung für die Erhaltung von Sprachrechten und von Diversität ein, die Sprachrechte werden jedoch oft nicht für jeden geltend gemacht, sondern nur für die Angehörigen der «authentischen Nationen». «Diversität» und «Toleranz» werden nur innerhalb der Staatsnation gefordert. Innerhalb der eigenen Minderheitsnation jedoch wird weiterhin das Ideal der nationalen Sprachhomogenität angestrebt.

\section{Bibliographie}

Ahlzweig, Claus, Muttersprache - Vaterland. Die deutsche Nation und ihre Sprache, Opladen, Westdeutscher Verlag, 1994.

Anderson, Benedict, Die Erfindung der Nation, Frankfurt am Main, Campus, ${ }^{2} 1993$ $\left({ }^{1} 1983\right)$.

Arenas Sampera, Joaquin, La immersió lingüistica: escrits de divulgació, Barcelona, La Llar del Llibre, 1986.

Arenas Sampera, Joaquin, Assaigs contemporanis, Barcelona, La Llar del Llibre, 1991.

Argente, Joan A., et al., Una nació sense estat, un poble sense llengua?, Els Marges 15 (1979), 3-13 (http://barcelona.indymedia.org/newswire/display/62487/index. php, 09. 03.2005).

Badia i Margarit, Antoni María, Llengua i nacionalisme: dos comentaris, Treballs de Sociolingüística Catalana 7 (1988), 11-29.

Bauernschmidt, Barbara, Der Umgang mit der Sprachenfrage in Katalonien seit 1975, Hispanorama 86 (1999), 43-50.

Blommaert, Jan (ed.), The Politics of Multilingualism and Language Planning. Proceedings of the Language Planning Workshop held at the Political Linguistics Conference in Antwerpen, December 1995, Antwerpen, Wilrijk, 1996.

Bochmann, Klaus, et al., Sprachpolitik in der Romania: zur Geschichte sprachpolitischen Denkens und Handelns von der Französischen Revolution bis zur Gegenwart, Berlin/New York, de Gruyter, 1993.

Böke, Karin, et al., Vergleichende Diskurslinguistik. Überlegungen zur Analyse national heterogener Textkorpora, in: Karin Böke/Thomas Niehr (edd.), Einwanderungsdiskurse. Vergleichende diskurslinguistische Studien, Wiesbaden, Westdeutscher Verlag, 2000, 11-36.

Branchadell Gallo, Albert, La normalitat improbable: obstacles a la normalització lingüistica, Barcelona, Ed. Empúries, 1996.

Branchadell Gallo, Albert, Liberalisme i normalització lingüística, Barcelona, Ed. Empúries, 1997.

Busse, Dietrich, Historische Semantik. Analyse eines Programms, Stuttgart, KlettCotta, 1987.

Dietl, Andreas, Regionalstaaten im Wettbewerb. Das Programm des Europa der Regionen lebt von Kulturchauvinismus und wirtschaftlichen Partikularinteressen, 
jungle world, 06.09.2000 (http://www.nadir.org/nadir/periodika/jungle_world/_2000/ 37/07a.htm, 15.04.2005).

En castellano también, por favor. Manifiesto por la tolerancia lingüística en Cataluña, $A B C$ : 22.5.94 (http://www.tolerancia.org/web-ant/Documentos/Manifiestos/ manitolecast.htm, 15.04.2005).

Foucault, Michel, Dispositive der Macht. Michel Foucault über Sexualität, Wissen und Wahrheit, Berlin, Merve, 1978.

Foucault, Michel, Archäologie des Wissens, Frankfurt am Main, Suhrkamp, 1981.

Foucault, Michel, Die Ordnung des Diskurses, Frankfurt am Main, Fischer, 1993, $\left({ }^{1} 1974\right)$.

Gardt, Andreas, Sprachpatriotismus und Sprachnationalismus. Versuch einer historisch-systematischen Bestimmung am Beispiel des Deutschen, in: Andreas Gardt/ Ulrike Haß-Zumkehr/Thorsten Roelke (edd.), Sprachgeschichte als Kulturgeschichte, Berlin/New York, de Gruyter, 1999, 89-113.

Kabatek, Johannes, «Auto-odi»: Geschichte und Bedeutung eines Begriffs der katalanischen Soziolinguistik, in: Gabriele Berkenbusch/Christine Bierbach (edd.), Zur katalanischen Sprache: historische, soziolinguistische und pragmatische Aspekte (vol. 2 der Reihe: Axel Schönberger (ed.), Akten des 2. Gemeinsamen Kolloquiums der Deutschsprachigen Lusitanistik und Katalanistik. Katalanistischer Teil), Frankfurt am Main, Domus Ed. Europea, 1994, 159-173.

Kabatek, Johannes, Minderheitenforschung und Normalität, in: Dieter Kattenbusch (ed.) Minderheiten in der Romania, Wilhelmsfeld, Egert, 1995, 25-31.

Link, Jürgen, Versuch über den Normalismus: wie Normalität produziert wird, Opladen, Westdeutscher Verlag, 1997.

Link, Jürgen, Diskursive Ereignisse, Diskurse, Interdiskurse: Sieben Thesen zur Operativität der Diskursanalyse, am Beispiel des Normalismus, in: Hannelore Bublitz et al. (edd.), Das Wuchern der Diskurse. Perspektiven der Diskursanalyse Foucaults, Frankfurt am Main, Campus, 1999, 148-161.

Manifiesto de los 2300. Por la igualdad de derechos lingüísticos en Cataluña, Diario 16, 12.3 .81 (http://www.nodulo.org/bib/drio/19810125.htm, 15. 04.2005).

Mar-Molinero, Clare, The Politics of Language in the Spanish Speaking World: from Colonisation to Globalisation, New York/London, Routledge, 2000.

Moll, Aina, Por la normalización lingüística de Cataluña. Serie de artículos de Aina Moll, Directora General de Política Lingüística, Barcelona, Dep. de Cultura i Mitjans de Comunicació de la Generalitat de Catalunya, 1981.

Niehr, Thomas/Böke, Karin, Diskursanalyse unter linguistischer Perspektive - am Beispiel des Migrationsdiskurses, in: Reiner Keller et al. (edd.), Handbuch Sozialwissenschaftliche Diskursanalyse/Forschungspraxis, Opladen, Leske, vol. 2: Budrich, 2003, 325-353.

Ninyoles, Rafael, Conflicte lingüístic valencià: substitució linguística $i$ ideologies diglòssiques, Valencia, Eliseu Climent, 1995.

Oppenrieder, Wilhelm/Thurmair, Maria, Sprachidentität im Kontext von Mehrsprachigkeit, in: Nina Janich (ed.), Sprachidentität - Identität durch Sprache, Tübingen, Narr, 2003, 39-60.

Pujol, Jordi, Discurs del Molt Hble. Sr. Jordi Pujol i Soley, President de la Generalitat de Catalunya, 30. 06. 1985, in: Congrés Internacional de la Llengua Catalana (ed.), Segón Congrés Internacional de la Llengua Catalana I. Convocatòria. Inauguració. Clausura. Conclusions. Congresistes, Barcelona, 1989, 31-34.

Pujol, Jordi, Discurs de Jordi Pujol al Parlament de Catalunya en el debat sobre l'orientació política del Govern de la Generalitat, 05. 10. 1988, in: Jordi Pujol, El programa polític del Govern de la Generalitat per als anys 1988-1992. Discursos del President de la Generalitat al parlament de Catalunya. 21 de juny $i 5$ d'octubre de 1988, Barcelona, Generalitat de Catalunya, 1989, 41-85. 
Pujol, Jordi, Acte institucional commemoratiu del 15è aniversari d'autogovern de Catalunya, Palau de la Generalitat, Barcelona, 20.03. 1995, in: Jordi Pujol, Paraules del President de la Generalitat. Gener - desembre 1995, Barcelona, Generalitat de Catalunya, 1996, 160-171.

Pujol, Jordi, «Qué representa la llengua a Catalunya?» Palau de Congressos de Montjü̈c, Barcelona, 22. 03. 1995, in: Jordi, Pujol, Paraules del President de la Generalitat. Gener - desembre 1995, Barcelona, Generalitat de Catalunya, 1996, 174201.

Schlieben-Lange, Brigitte, Soziolinguistik: Eine Einführung, Stuttgart/Berlin/Köln, Kohlhammer, ${ }^{3} 1991$.

Schmidt-Felzmann, Anke, Kultureller und politischer Nationalismus: Unabhängigkeitsbestrebungen in Katalonien und Schottland, Germersheim am Rhein, Centro de Estudios Latinoamericanos, 2001.

Schulze-Mermeling, Dietrich, Nationalitätenkonflikte in Westeuropa, in: Jürgen Elsässer/Andrea Komlosy (edd.), Krisenherd Europa. Nationalismus, Regionalismus, Krieg, Göttingen, Die Werkstatt, 1994, 43-51.

Una ley con 11 años de vida, in: El País, 24.12.1994.

Vallverdú, Francesc, La normalització lingüística a Catalunya, Barcelona, Laia, 1979.

Vallverdú, Francesc, L'ús del català. Un futur controvertit, Barcelona, Ed. 62, ${ }^{2} 1992$ $\left({ }^{1} 1990\right)$.

Weisgerber, Leo, Die deutsche Sprache im Aufbau des deutschen Volkslebens, in: Gerhard Fricke/Franz Koch/Klemens Lugowski (edd.), Von deutscher Art in Sprache und Dichtung, Stuttgart/Berlin, Kohlhammer, 1941, 3-41.

Wodak, Ruth, Zur diskursiven Konstruktion nationaler Identität, Frankfurt am Main, Suhrkamp, 1998.

Marburg an der Lahn

KIRSTEN SÜSELBECK 